\title{
El uso de medios de votación electrónica. Una mirada global de su problemática y las exigencias normativas
}

\author{
Miguel González Madrid ${ }^{1}$
}

\section{Resumen}

Este artículo se ocupa de algunas de las vicisitudes del denominado "voto electrónico" en el mundo, en asociación directa con la cuestión de la regulación idónea con la que es necesario consolidar la seguridad y confiabilidad de su uso, pero prioritariamente con la finalidad de dar seguridad y confianza a los votantes, para proteger y garantizar sus derechos político-electorales, y a los funcionarios electorales que cargan con la responsabilidad de realizar elecciones democráticas y apegadas a la ley. El planteamiento toma como punto de partida una revisión general de la problemática relativa a la desconfianza que ha generado la posibilidad de vulneración de los sistemas de votación electrónica, a pesar de los sucesivos desarrollos tecnológicos para disuadirla o eliminarla, y pone énfasis en los estándares y principios técnicos y jurídicos que son necesarios para favorecer el blindaje de los sistemas de votación electrónica y, fundamentalmente, proteger y garantizar esos derechos político-electorales, con la convicción de que la prioridad de todo tipo de sistema electoral es la ciudadanía y el principio de secrecía que ampara la manifestación de la voluntad colectiva en elecciones populares.

Palabras clave: Voto electrónico, boleta electrónica, derechos electorales, regulación electoral, principios.

\begin{abstract}
This article deals with some of the vicissitudes of the so-called "electronic vote" in the world, in direct association with the question of the suitable regulation with which it is necessary to consolidate the safety and reliability of its use, but primarily with the aim of giving security and trust for voters, to protect and guarantee their political-electoral rights, and for electoral officials who bear the responsibility of carrying out democratic elections and abiding by the law. The approach takes as a starting point a general review of the problems related to mistrust that has generated the possibility of violation of electronic voting systems, despite successive technological developments to deter or eliminate $i t$, and emphasizes standards and technical and legal principles that are necessary to favor the shielding of electronic voting systems and, fundamentally, protect and guarantee these political-electoral rights, with the conviction that the priority of all types of electoral system is citizenship and the principle of secrecy that protects the manifestation of the collective will in popular elections.
\end{abstract}

Keywords: Electronic voting, electronic ballot, electoral rights, electoral regulation, principles.

\section{Introducción}

A propósito de serias y efectivas dificultades para realizar elecciones en muchas partes del mundo debido a la pandemia del COVID-19, ${ }^{2}$ el debate sobre la incorporación de sistemas de voto electrónico en elecciones populares parece haber entrado en una ronda de revaloración de los medios de votación que simplifiquen la emisión y recepción de votos de los ciudadanos habilitados para ejercer su derecho político a elegir a sus representantes y gobernantes, pero que, además, ayuden a evitar las aglomeraciones innecesarias en los centros de votación, casillas y similares. Desde luego, la salvaguarda de los derechos político-electorales importa; incluso, con mayor razón, esa función debe ser maximizada.

Es probable que la búsqueda de medios de votación que ayuden a reducir tiempos de votación y evitar esas aglomeraciones de votantes tenga que pasar por la fase terminal de la evolución de las máquinas electrónicas de almacenamiento digital de votos a las boletas de impresión electrónica de los votos, en una transición que combine la

\footnotetext{
${ }^{1}$ Maestro en Derecho Electoral por la Universidad del Valle de Tlaxcala (UVT) y Politólogo por la Universidad Autónoma Metropolitana (UAM). Investigador y Docente de la UAM en líneas de investigación sobre elecciones, democracia, derechos fundamentales, control constitucional, teorías del Estado, políticas públicas y gobiernos locales. Correo electrónico: $\underline{\text { mgmundouno@yahoo.com.mx }}$

${ }^{2}$ Véase al respecto Panorama global del impacto del COVID-19 en las elecciones, un informe exhaustivamente documentado de IDEA Internacional sobre las dificultades que enfrentan las elecciones populares programadas para su realización en 2020, en diversos lugares del mundo. Link: https://www.idea.int/es/news-media/multimediareports/panorama-global-del-impacto-del-covid-19-en-las-elecciones. El documento fue publicado en línea el 23 de marzo de 2020, pero su actualización es permanente.
} 
tradición del uso de papeletas impresas con el uso de instrumentos electrónicos para dar certeza de que los votos cuenten efectivamente y que la posibilidad de fraude se reduce al máximo posible. Pero esta podría tornarse una larga transición, porque hay múltiples factores que tendrían que superarse para dar forma a la era de lo que yo llamaría el voto digital-impreso $\mathrm{y}$, sobre todo, para abandonar esa imagen de jornadas electorales con aglomeraciones, hacinamiento y continuas filas para seguir y agotar un procedimiento establecido en la ley para la manifestación popular de manera dosificada. Incluso, como parte de esa transición, es posible que la modalidad de voto electrónico remoto (por la vía de internet, a través de dispositivos móviles o de estaciones fijas, independientemente del tipo de red y de protocolo de transmisión de datos) alcance un nivel más alto de utilidad o preferencia.

En la actualidad, debido al elevado riesgo sanitario que ha provocado la propagación mundial del coronavirus SARSCoV-2 causante de dicha enfermedad, las autoridades organizadoras de distintos tipos de elecciones populares, en diversos países y demarcaciones subnacionales, han tenido que suspender temporalmente la realización de elecciones programadas en la ley o, al menos, de los actos previos y de campaña del proceso; y, por dondequiera, en tanto, se plantea qué medios materiales -o una combinación de medios- pueden ser efectivos y confiables para votar: ¿El correo postal, como parece que se privilegiará en las elecciones presidenciales estadounidenses, pero que ha sido también un mecanismo común en otros países? ¿Las jornadas de dos días (como en Italia, para elegir diputados y senadores) o hasta tres días (como en los consulados generales de España, en el exterior)? ¿El voto electrónico remoto vía internet, sea desde casa, en estaciones autorizadas o desde el smartphone? También, nuevamente, en muchos lugares se discute sobre el voto electrónico como uno de los medios que puede ayudar a reducir los tiempos de emisión-recepción de votos y, sobre todo, resolver las aglomeraciones de votantes (consideradas como uno de los factores propicios a la propagación del nuevo coronavirus).

Desde otra perspectiva, prácticamente todos los actores y las autoridades involucradas en los procesos electivos se han planteado interrogantes sobre el futuro de las elecciones, las formas de renovación de la representación política, las atribuciones administrativas y jurisdiccionales para modificar los calendarios electorales, el uso de medios de votación que superen las típicas aglomeraciones de los votantes durante las jornadas comiciales, etcétera. En esta agregación de interrogantes, es indudable que también se plantea la urgencia de realizar los procesos pendientes de 2020 y los de años venideros conforme a nuevas realidades sociales y políticas que viven los votantes, con el auxilio de las tecnologías electrónicas y con el menor riesgo de contagio posible de virus entre ellos.

Supongo que esas interrogantes estarán flotando llamativamente en el ambiente de propagación del nuevo coronavirus, hasta que comiencen las campañas de vacunación para lograr la inmunización de todas las personas en el mundo, y eso constituye una fuerte motivación para revisar inicialmente cómo es que los medios de votación electrónica fueron apareciendo (bajo las denominaciones comunes de "urna electrónica", "voto digital", "voto electrónico") al amparo de la revolución informática y microelectrónica; y, en especial, importa plantearse qué tipo de estándares y principios han sido propuestos para que su uso sea mayormente seguro y confiable, tanto desde el punto de vista informático como jurídicoelectoral. La temprana reunión de evidencias empíricas sobre la débil seguridad informática de los equipos de votación electrónica, en particular de aquellos que estaban diseñados con sistemas de registro directo y que eran utilizados en redes, así como los escándalos de hackeo y la publicitación de casos de vulnerabilidad de los dispositivos informáticos en sistemas posteriores, parecen no ser suficientemente convincentes como para desalentar un retorno al debate sobre las bondades de las tecnologías de votación electrónica; pero el debate es más amplio cuando se extiende al terreno de las regulaciones de su uso en votaciones populares, y ahí es en donde puede estar la clave para avanzar a una nueva etapa de desarrollos tecnológicos, la que de hecho parece haber iniciado con la creación de la boleta electrónica y la impresión de comprobantes del sentido de la decisión de los votantes. Gracias a las exigencias normativas electorales, los desarrollos tecnológicos ya no parecen avanzar en solitario, al grado de que incluso la microelectrónica se ha fusionado con el tradicional papel.

Por tanto, me referiré en adelante grosso modo a dos líneas de investigación y de interés práctico sobre el desarrollo de medios electrónicos de votación, pero en particular señalaré que este tipo de medios no puede ser utilizado en elecciones populares sin la imperiosa necesidad de proteger y garantizar los derechos de los votantes y los principios que rigen todo proceso electoral democrático a través de una regulación idónea, basada en principios jurídicos, que den prioridad a los derechos de los votantes. 


\section{El interés histórico por el uso de artefactos y tecnologías de votación}

Los estudios especializados y de divulgación auspiciados de manera individual o por organismos electorales y centros de investigación acerca de las votaciones populares y democráticas en las cuales se utiliza algún medio o artefacto (aparatos, máquinas, instrumentos o mecanismos) de tipo electrónico ${ }^{3}$, han proliferado en el mundo occidental desde finales de la década de 1990, en coincidencia con: a) el auge de la doble revolución informática y micro-electrónica que tuvo como resultado la creación de redes y sistemas operativos informáticos ${ }^{4,5}$ y la consecuente superación de la etapa de las máquinas mecánicas y las analógicas ${ }^{6}$; b) la expansión de las tecnologías de telecomunicaciones digitalizadas e inalámbricas (Jódar Marín, 2010; y DRCCT, 2005) en paralelo con una progresiva sustitución de cableados de cobre por redes de fibra óptica (véase Ganuza, Perca y Viecens, 2011); y c) el vertiginoso surgimiento de la llamada "sociedad de la información" o "sociedad del conocimiento" o "sociedad de la comunicación". 7 Todas estas

\footnotetext{
${ }^{3}$ Para evitar una redacción extensa a la hora de referirnos a esos aparatos, máquinas, instrumentos o mecanismos de votación electrónica, generalmente nos referiremos a ellos con otra expresión: medios de votación electrónica. Pero también utilizaré la denominación genérica que agrupa a todos ellos: artefactos.
}

${ }^{4}$ Claudio Katz (2003-04: 5-21) explica esa revolución tecnológica en los siguientes términos: "El desarrollo de aparatos que potencian el uso económico de la información mediante la generación y retroalimentación de los datos utilizados en la actividad laboral es el eje del cambio tecnológico actual. Esta transformación comenzó con la revolución microelectrónica y la miniaturización de los componentes de transmisión eléctrica que permitieron acelerar el procesamiento de la información y generalizar el uso de las computadoras y las redes. La memoria de los chips, la velocidad de los microprocesadores y el poder de Internet son los barómetros de la intensidad que tiene esta innovación".

${ }^{5}$ De acuerdo con David Luis la Red Martínez (2012: 3), un sistema operativo es un "grupo de programas de proceso con rutinas de control necesarias para mantener continuamente operativos dichos programas", los cuales permiten, entonces, el control de una computadora (su microprocesador), desde el encendido hasta el procesamiento de información diversa de interés para el usuario, mediante aplicaciones informáticas.

${ }^{5}$ Sin duda, los sociólogos Manuel Castells (1997) y Armand Mattelart (2002) contribuyeron a explicar lo que también aquél llamó la "sociedad red" (complementada con el "Estado red"), a partir de los años de 1980, en el contexto del surgimiento de la globalización, la aparición de las redes informáticas y la internet, así como la expansión de las relaciones sociales y productivas a través de entramados de múltiples centros de poder y de mecanismos de coordinación entre los actores: la sociedad de los años de 1980 y posteriores. Una frase de Castells (1997: 57) describe correctamente el corte tecnológico de esa era: "La tecnología de la información es a esta revolución lo que las nuevas fuentes de energía fueron a las sucesivas revoluciones industriales, del motor de vapor a los combustibles fósiles e incluso a la energía nuclear [...]".

${ }^{6}$ Alex Cosper resume de manera sencilla y comprensible la historia de las computadoras, desde la misma aparición de la denominación hasta la etapa de sustitución de las máquinas mecánicas y analógicas: "La definición original de la palabra "computadora" fue de una persona que hizo cálculos. Esta definición se remonta a la década de 1600 y se extiende a la mitad del siglo 20 [sic], cuando el término "computadora" comenzó a referirse a una máquina. La computadora se basa en el mismo concepto que el ábaco que se remonta a muchos siglos. La tecnología hizo un salto de gigante con tarjetas perforadas, introducida por Joseph-Marie Masquard en 1801". "La palabra "computadora" ha cambiado de significado en las últimas décadas; sin embargo, la computadora electrónica que nosotros pensamos en tiempos modernos se desarrolló a lo largo de la segunda mitad del siglo 20. Su popularidad como un artículo para el hogar surgió en la década de 1980 tras la llegada de los sistemas operativos de Apple y Microsoft que mezclaron gráficos y textos, en sustitución de los sistemas de sólo texto de la década de 1970. En la década de 1990, las computadoras incorporaron una mejor comunicación y aplicaciones multimedia, y se convirtió en una parte indispensable de la vida cotidiana para millones de personas" (Véase su colaboración "Historia y evolución de las computadoras", en línea: http://www.ehowenespanol.com/historia-cronologia-computadoras-personalessobre_264236/).

${ }^{7}$ Al respecto, véase la extensa obra de Manuel Castells, La era de la información. Economía, sociedad y cultura, siglo XXI editores, México, 1998. La publicación de la obra en tres volúmenes, correspondiente a la segunda edición ampliada, fue realizada por Alianza Editorial, colección Libros Singulares, España, a partir de 2003: volumen I "La sociedad red", volumen II "El poder de la identidad" y volumen III "Fin de milenio". 
expresiones confluyeron en la llamada era de la globalización y quedaron incluso fusionadas en una macrodenominación de uso común hoy en día que aglutina varias dimensiones técnico-socio-culturales: las

“tecnologías de la información y el conocimiento" o -por sus siglas- TIC’s (véase Sunkel, Trucco y Möller, 2011; Ballinas Valdés, 2011; y Hilbert y Cairó, 2009).

Del mismo modo, el uso de artefactos electrónicos con diversas aplicaciones informáticas o soportes lógicos (software $)^{8}$, comenzó a extenderse en los campos de la industria, los servicios financieros y escolares, incluso en la organización de las elecciones populares, una vez que apareció la internet y la interfaz gráfica de usuario, ${ }^{9}$ en los años de 1990, con lo cual también fue abierta una ventana hacia una realidad virtual de los procedimientos electorales. Al extenderse también al campo electoral, dichos estudios no se limitaron sólo a señalar o recomendar las bondades de las máquinas, instrumentos o aparatos, debido a su eficiencia en el procesamiento de datos y al intercambio de éstos con una multiplicidad de usuarios en tiempo real, sino que también señalaron la necesidad de diseñar software para el usuario apropiado a cada tipo de actividad o necesidad práctica, además de hardware a partir de las revoluciones de la microelectrónica y el uso de nuevos materiales de almacenamiento de información y transmisión de señales. Así, en los ordenamientos legales fueron incorporadas normas para regular las diversas actividades afectadas por la informática: por ejemplo, para la sistematización de bases de datos personales, el procesamiento y la sistematización de información gubernamental, la creación de nuevos servicios bancarios, el procesamiento de información obtenida por encuestas, etcétera.

Es evidente que el eje de unión entre el nivel de interés teórico-jurídico y el de desarrollo tecnológico (de software y hardware) en materia de voto electrónico parece estar dado por el hecho de que, en principio, hay una omisión generalizada por vincular normativamente el uso de máquinas de votar, localizable entre finales del siglo XIX y mediados de la década de 1960. Esto comenzó a cambiar desde 1965, un año después de que en los Estados Unidos de América (EE.UU.) se implementara el sistema de tarjetas perforables ${ }^{10,11}$,

De manera complementaria, otros autores han propuesto el concepto de "economía de la información", fundamentalmente en conexión con el debate sobre toma de decisiones entre competidores en el mercado: véase, por ejemplo, Thomas Otter y Mónica Cortez (2003); además, véase el Informe sobre la Economía de la Información, publicado anualmente por la Conferencia de las Naciones Unidas sobre Comercio y Desarrollo, UNCTAD, especialmente 2012 y 2013.

${ }^{8}$ Sobre la traducción de la expresión "software", Corina Schmelkes y Nora Elizondo Schmelkes (2010: 129) señalan lo siguiente: "En muchas ocasiones, la palabra software se traduce como «paquete» o «programa»; pero esto es una equivocación, pues un programa puede ser sólo una parte del software. Las personas que tratan de cuidar el idioma afirman que lo correcto es decir logical o «soporte lógico»".

${ }^{9}$ De la interfaz clásica de los lenguajes de computación por comandos (CLI), a principios de los años de 1990 se transitó a la interfaz de texto (TUI) y de ahí a la interfaz gráfica de usuario (GUI) con uso de colores, iconos, símbolos, figuras y cuerpos geométricos, y mapas de navegación visual en pantalla que lograron dinamizar la interacción entre el usuario y la computadora. En etapas posteriores, desde el ocaso del siglo XX, se desarrollarían la computación gráfica, la multimedia, la realidad virtual 3D y la integración de mundos reales y virtuales para dar forma a "realidades aumentadas" (véanse al respecto: Heras Lara y Villarreal Benítez, 2004; y Luzardo Alliey, 2009).

${ }^{10}$ Esta extensa cita textual corresponde a Pedro Villavicencio Guardia y es parte de sus apuntes del curso "Sistemas y Tecnología de Información", publicado en línea el 29 de noviembre de 2012, en http://pantaleon0.webnode.es/news/aplicacion-de-tecnologia-en-el-sistema-electoral/, y describe con claridad las características del uso de las tarjetas perforables (utilizo cursivas para su transcripción):

En los sistemas de perforación de tarjetas, los electores hacen hoyos en las tarjetas con ayuda de un aparato especial, para indicar el candidato a quien otorgan su voto. Después de votar, el elector introduce la tarjeta en una computadora que tiene un mecanismo de tabulación, o también puede introducir la tarjeta en una urna, que posteriormente se traslada a instalaciones centrales para tabular su contenido. / Las dos clases de tarjetas para perforar que se usan en los Estados Unidos son la "votomatic" y la "datavote". Los puntos en donde se deben realizar las perforaciones, en la tarjeta votomatic, están señalados con números. El número de perforación es el único tipo de información que se imprime en la tarjeta. La lista de los candidatos y las instrucciones para perforar se imprimen en un libro por separado. En la tarjeta datavote, el nombre del candidato se imprime en la papeleta junto al lugar en donde se debe hacer la perforación. / Las tarjetas perforables y las computadoras para escrutarlas, se usaron por primera vez en los Estados Unidos en 1964, para las elecciones presidenciales primarias que se realizaron en dos condados del Estado de Georgia. / Aunque muchos de los sistemas para perforar tarjetas que se usan en los Estados Unidos están siendo reemplazados por tecnologías más 
y cuando en Holanda se manifestó un interés específico por sentar las primeras bases jurídicas para el uso de un subsistema electrónico electoral. Pero fue en la segunda mitad de la década de 1990 que el interés por los marcos regulatorios jurídicos se intensificó, primero, como una de las respuestas a las variadas revelaciones acerca de los riesgos de seguridad informática que estaban presentando los sistemas computarizados de Registro Electrónico Directo (DRE, por sus siglas en inglés) en varios países del mundo y, enseguida, como una respuesta a la fragmentación y heterogeneidad de los sistemas de votación empleados en los EE. UU., con relación directa a los cuestionados resultados electorales presidenciales de 2000 en este país, particularmente en los condados de La Florida ${ }^{12}$. La Ley estadounidense HAVA (Ley de "Ayude a América a Votar") de 2002, es un ejemplo claro de urgente necesidad de regulación jurídica, si no unificada, sí diseñada conforme a estándares mínimos en un entorno altamente heterogéneo de autonomía de los estados de la Unión Americana en materia de elecciones populares. ${ }^{13}$

\section{Las grandes líneas de investigación sobre voto electrónico}

En el campo de los estudios sobre el voto electrónico, suelen ser distinguidos dos grandes líneas de investigación y de interés práctico: a) el de los variados desarrollos tecnológicos (véase, por ejemplo, Urday Chávez, 2012; Figueroa González, 2006; y García Zamora, 2005); y b) el del diseño de regulaciones apropiadas al uso de nuevas tecnologías (Carrau, 2010: 157-162; Adames Suari, 2009; Romero Flores y Téllez Valdés, 2010; Lizeaga Romero, 2002: 3-4; Fernández Riveira, 2007: 37-65; Delgado-Iribarren $\mathrm{G}^{\mathrm{a}}$-Campero, 2008; y Dirección Nacional Electoral, 2005). En algunos países se avanzó en ambas líneas, sobre todo ahí en donde las elecciones populares se han realizado prácticamente al cien por ciento, como en Brasil o en Venezuela, o bien en donde la autoridad judicial ha intervenido para señalar que, en el uso específico de máquinas de votación electrónica, es necesario contar con regulaciones ad hoc,

avanzadas, muchos electores continúan utilizándolos. Los sistemas para perforar tarjetas fueron usados por el 37.3\% de los electores de Estados Unidos para la elección presidencial de 1996.

A su vez, véase el trabajo de Antonio De Cabo y José Manuel Sierra (De Cabo y Sierra, 2001: 77), quienes señalan lo siguiente: "Las elecciones se desarrollan en Estados Unidos por condados, cada condado organiza las elecciones y sigue procedimientos de voto diferentes, disponiendo materialmente las papeletas y resto de materiales para la votación. Existen varios procedimientos mecanizados de voto, en lo que aquí importa, en Florida, entre otros, se utiliza el de las "Punching cards' (tarjetas perforables). Las tarjetas perforables se introducen en un marco con perforaciones. El votante atraviesa con un punzón o estilete la papeleta (sostenida por el marco) en las perforaciones correspondientes al candidato de su elección y deposita su voto. Posteriormente una máquina ilumina la papeleta y detecta la luz que atraviesa las perforaciones. Si un solo rayo de luz atraviesa la papeleta (por elección), estamos ante un voto válido".

${ }^{11} \mathrm{El}$ inicio de la segunda etapa del interés por diseñar legislaciones estandarizadas e idóneas para el ejercicio del voto con nuevos instrumentos coincidió en 1965, en los EE. UU., con la aprobación de la Voting Rights Act of 1965 (Ley de Derechos al Voto de 1965) que prohibió las prácticas discriminatorias y, por tanto, favoreció a los ciudadanos de origen afroamericano. Esta ley -basada en la vigesimocuarta enmienda a la Constitución de los EE.UU. proyectada en 1962 y ratificada en 1964, protegió el derecho a votar y erradicó una serie de requisitos discriminatorios relacionados con alfabetización y pago de impuestos.

${ }^{12}$ El trabajo de María Rosa Gentile Martínez (2007), "Monografía sobre el Estado de la Florida", es uno de los pocos documentos que describen con detalle el contexto de la elección presidencial estadounidense de 2000 y los problemas suscitados en varios de los condados de ese Estado (26 utilizaron tarjetas perforables; 33, escáneres ópticos; 2, máquinas de palanca; y 1, papeletas impresas), lo cual llevó a los demócratas a pedir un recuento manual de votos y pusieron así en entredicho el triunfo del candidato republicano George Bush, además de que las críticas al sistema electoral incluyó el uso de "equipos obsoletos" de votación.

${ }^{13}$ De acuerdo con la Election Assistance Commission de los USA, "El congreso de los Estados Unidos aprobó la Ley de Ayude a América a Votar (HAVA) del 2002 para hacer reformas dramáticas al proceso electoral de la nación. HAVA procura mejoras a los sistemas de votación y acceso a las elecciones que fueron identificados siguientes las elecciones de 2000. / HAVA crea nuevos estándares mandatarios mínimos para los estados en varias áreas clave de administración electoral. La ley provee fondos a los estados para ayudarlos a cumplir con estos estándares nuevos, reemplazar sistemas de votación y mejorar la administración de las elecciones. HAVA estableció a la EAC para proporcionar fondos de HAVA a los estados y para asistirlos a cumplir con los requerimientos de HAVA. La EAC también es responsable de desarrollar directrices para sistemas de votación y administrar el primer programa de certificación de sistemas de votación del gobierno federal" (consulta en línea, con fecha 20 de enero de 2014, desde: http://archives.eac.gov/translation/copy_of_en-espanol/ley-de-ayude-a-america-a-votar-hava). 
es decir normas que permitan controlar su uso, su funcionamiento y su incidencia en relación con los derechos de los usuarios y/o ciudadanos, y que no sólo autoricen a la entidad organizadora de las elecciones a incorporar sistemas de votación electrónica.

Sin embargo, subsiste un problema en el uso progresivo de máquinas o artefactos electrónicos en elecciones populares y democráticas, a la luz de la exigencia general de garantizar plenamente una serie de derechos político-electorales de los ciudadanos y, por tanto, de satisfacer exigencias de transparencia y confiabilidad en ese uso para dar seguridad jurídica a tales derechos. El problema consiste, por un lado, en que los diseños tecnológicos deben adecuarse simultáneamente a esas exigencias, incluso con regulaciones jurídicas incipientes, y no sólo a las revoluciones informáticas. Los fabricantes de ese tipo de máquinas electrónicas trabajan continuamente para diseñar nuevos sistemas y crear nuevas arquitecturas de hardware que puedan cumplir -además de las regulaciones técnicaslas regulaciones que incluyen normas jurídicas de validez general orientadas a la salvaguarda de derechos humanos y, en particular, de derechos político-electorales. ${ }^{14}$

De ese modo, se comprende que el uso de máquinas de votación electrónica y de instrumentos similares (como la boleta electrónica) no puede pasar inadvertido para el derecho electoral. En palabras de Rodolfo Romero Flores y Julio Alejandro Téllez Valdés (2010: 93), "el derecho electoral constituye una aplicación del derecho constitucional, que establece normativamente una serie de condiciones para ejercitar los derechos políticos-electorales del ciudadano, y que dispone para su materialización, de una serie de principios electorales orientadores de las normas comiciales que regulan su contenido".

En ese tono, el derecho electoral dispone de herramientas de análisis para observar si las leyes electorales carecen o no de reglas y procedimientos debidos cuy a finalidad consiste en otorgar funciones a la autoridad electoral y en reconocer la oportunidad a los votantes para ejercer control del acto electoral y, de esa manera, salvaguardar el ejercicio de derechos de los votantes conforme a principios jurídicos. Del mismo modo, de acuerdo con Romero Flores y Téllez Valdés (2010: 94), "el derecho electoral norma una serie de instituciones y procedimientos de naturaleza electoral, que se traducen del plano legal al plano operativo, en mecanismos de desarrollo de actividades específicas tendientes a la renovación periódica de órganos representativos constitucionales, vía las elecciones", y "entre estas actividades de desarrollo se encuentran los procedimientos de votación, que son sustancialmente modificados cuando se incorporan mecanismos de votación electrónica".

Ahora bien, en relación con las votaciones populares, cuyo desarrollo sigue una regulación específica y unos principios idóneos, la función institucional y el aprovechamiento de oportunidades para ejercer el control ciudadano del acto electoral se deben llevar a cabo mediante tareas de verificación o control ${ }^{15}$ de los aparatos e instrumentos utilizados, de las operaciones sucesivas durante la jornada electoral y de los resultados generados, previstos por reglas y procedimientos ex profeso y ad hoc, es decir, de manera específica e intencional, a la vez que con la idoneidad debida

${ }^{14}$ En ese tenor, en México es urgente discutir con seriedad la pertinencia de crear algún tipo de normas que (a) autoricen expresamente el uso de medios electrónicos de votación, pero que además (b) indiquen las reglas y los procedimientos específicos para su implementación y control con base en principios que rigen los sistemas electorales democráticos y, sobre todo, (c) enuncien la prioridad de los derechos político-electorales como derechos que deben ser protegidos y garantizados en todo momento.

${ }^{15}$ María José Aguilar Idáñez y Ezequiel Ander-Egg (1994) definen la función de control de la función de evaluación. La evaluación implica un proceso de análisis, ponderación o juicio sobre una situación o una acción determinada, los recursos empleados, sus resultados y consecuencias, y se sirve, para sus fines, de instrumentos diversos de medición, estimación, seguimiento y control. La función de control consiste en "una verificación de resultados" o "una verificación de algo". Maximiliano Cristiá (2009) examina la cuestión de la pruebas de software a través de funciones de validación y verificación; y, para él, mientras la validación es un acto terminal o, en su caso, intermedio, porque significa autorizar la terminación o salida de un producto que cumple con una lista de especificaciones o con las expectativas de los clientes o beneficiarios (¿se está elaborando el producto o subproducto correcto y/o esperado?), la verificación se enfoca al proceso mismo como una concatenación de actos de comprobación y, por tanto, puede cumplirse en cualquier momento (¿se está elaborando el producto o subproducto correctamente o conforme a un programa?). En este sentido, "la verificación consiste en corroborar que el programa respeta su especificación, mientras que validación significa corroborar que el programa satisface las expectativas del usuario". Se desprende de esto que la verificación y validación (V\&V) van de la mano en tanto que permiten un control del proceso y la aprobación de resultados en un continuum (Zamora Hernández y Sanz Esteban, 2011: 18-19). Lo primero, mediante una "lista de verificación"; lo segundo, mediante una "lista de calificaciones", como en los tests psicológicos (Aiken, 2003). 
que requiere el tema. En una sociedad como la mexicana, en la cual la desconfianza en las elecciones ha sido una constante desde el siglo XIX, y no obstante que desde 1990 se han adicionado ingredientes normativos y accesorios para obtener de los electores mínimos de confianza, es más clara la necesidad de evitar que el arranque de un sistema de votación electrónica corra en una zona de indeterminación jurídica y de opacidad administrativa y operativa.

Por tanto, en la lógica de los Estados constitucionales democráticos de derecho, las regulaciones electorales deben sujetarse a principios que garanticen esos derechos y, por consecuencia, deben establecer mecanismos de control por parte de la misma autoridad electoral que organiza la elección, pero también por parte de los ciudadanos interesados en corroborar que su voto sea respetado en el mismo sentido que lo emitió. Si esto es así, entonces, no se trata de incorporar nuevos desarrollos tecnológicos en la realización de las votaciones populares, como si fuera una moda o con un propósito de evitar el rezago tecnológico o porque la ley escuetamente enuncia el uso de "instrumentos electrónicos" en algún momento del proceso electoral, sino que debe anteponerse a dicha incorporación tecnológica la finalidad del Estado constitucional y democrático de garantizar efectivamente los derechos político-electorales desde el diseño mismo de las normas aplicables, además de que ello puede ayudar a prevenir la violación de ese tipo de derechos. En consecuencia, en el diseño e implementación de todo sistema de votación popular y democrática el ciudadano debe ser la prioridad (como usuario, pero sobre todo como portador de derechos), mientras que los medios e instrumentos a utilizar deben conservar su carácter de accesorios de mayor o menor utilidad, mayor o menor comodidad.

En consonancia con lo anterior, me parece correcto el señalamiento de Romero Flores y Téllez Valdés (2010: 97) en relación con la premisa de que el voto electrónico también "se orienta a la materialización del principio de efectividad del sufragio", por lo que existe

[...] la necesidad de que el sufragio, primero en lo individual sea bien escrutado y computado, y segundo, cuando el sufragio individual se redimensiona y toma la forma de una decisión colectiva obligatoria, más que justificada la necesidad de que los resultados de las elecciones sean completamente ciertos y transparente para que no den lugar a suspicacia alguna y constituyan el fiel reflejo de la voluntad popular.

Conforme a estas consideraciones preliminares, es conveniente señalar que la implementación del voto electrónico, cual sea el medio que se prefiera, exige también condiciones jurídicas para establecer una regulación, a fin de facilitar la adopción de algún sistema específico de votación electrónica. Para ello, en términos generales, es conveniente que la ley establezca las características generales de dicho sistema y, por tanto, las funciones que deben realizarse con la máquina electrónica y otro tipo de instrumentos electrónicos. Al respecto, puede ser útil una descripción del sistema de voto electrónico presencial proporcionada por Rubén Martínez Dalmau (2011: 236), en la forma como parecía que podría operar en general, en una línea ascendente de desarrollo totalmente automatizado de los procesos de votación, que en cierto modo puso énfasis en el dominio del desarrollo tecnológico hasta entonces logrado, es decir, en la capacidad de la máquina electrónica para concentrar todas las operaciones asociadas al procedimiento del voto:

El voto electrónico presencial, también denominado red (Registro Electrónico Directo) o, en sus iniciales en inglés, DRE (Direct Recording Electronic Voting system), requiere de la presencia del votante en el sitio donde tiene lugar la votación -en el caso del voto electoral, la mesa correspondiente-, así como su conveniente identificación frente a los responsables de su acreditación. A continuación, tiene lugar la definición de la selección del elector a través de la presión de las opciones que la computadora le muestra en su pantalla. Las modalidades de diseño de la interface de la máquina son varias, y mejoran con el tiempo para facilitar el proceso. La intervención de la máquina sólo tiene lugar en cuanto al registro de la elección del votante, su contabilización y su transmisión al centro de datos que coordina la obtención de los resultados finales.

Sin embargo, en la medida en que uno de los grandes cuestionamientos que enfrentó el sistema DRE dominante a finales de los años de 1990 y principios del siglo XXI, de autocontención y almacenamiento oculto de datos, la atención pareció concentrarse en la preocupación señalada por Rebecca Mercuri consistente en lo siguiente: "cualquier programador puede hacer un código que muestre una cosa en la pantalla, grabe otra y hasta imprima un resultado diferente", ${ }^{16}$ además de la vulnerabilidad de la transmisión automática en red de los resultados almacenados en cada

${ }^{16}$ Holanda es considerado el país pionero en materia de voto electrónico, pues adoptó este sistema en 1965 en su legislación electoral, aunque fue hasta 1991 cuando autorizó el uso de máquinas electrónicas de votar y hasta 2006 cuando llevó a cabo su primera elección popular con este tipo de máquinas. Sin embargo, un año después dejó de emplear este tipo de sistemas, porque "Sin embargo, un mes y medio antes de la realización de dichas elecciones, un grupo de ciudadanos activistas autodenominado "We don't trust voting computers", conocido en español como "No confiamos en equipos de votación", logró mostrar en un programa de televisión la vulnerabilidad de los computadores encargados en registrar los votos, debido a falencias técnicas que permiten alterar el chip de registro en menos de 60 40 
máquina (Mercuri, 2001 y 2007; y Obremski, 2006: 146-147). Ante la posibilidad de riesgo señalado, comenzaron a aparecer alternativas híbridas o mixtas (Téllez Valdés, 2010: 24; Panizo Alonso, 2007: 18; y Puiggali, 2007) para limitar el uso de máquinas electrónicas a operaciones de emisión, registro y contabilización (o cómputo) de los votos, soportado todo ello en comprobantes para los votantes y actas oficiales de resultados in situ e independientemente de que el sistema estuviera asociado al uso de boletas electrónicas o no, porque la desconfianza de un sector de expertos y ciudadanos se finca precisamente en la posibilidad de alteración de resultados transmitidos en red -o almacenados en la memoria de una máquina - si se omiten procedimientos de verificación previa del sistema y en el arranque de la votación, como ocurre con el modo tradicional o convencional de escudriñar y computar los votos marcados en boletas de papel. ${ }^{17}$ El riesgo incluso subsistió durante la segunda década del siglo XXI para ciudadanos y autoridades electorales de distintas provincias argentinas, quienes han visto cómo se ha extendido en línea ascendente el uso del sistema de boleta única electrónica de la empresa Magic Software Argentina (MSA), como parte de su sistema vot-ar, cuando los detractores de esta variante hibrida de voto electrónico arguyeron que el chip de almacenamiento limitado y cerrado de dicha boleta también podía ser interferido mediante un receptor-transmisor externo -una simple aplicación instalada en un teléfono celular- próximo al lugar de emisión del voto, para leer la información, transferirla y alterarla en la forma de clonación de votos.

Ahora bien, la DRE (por sus siglas en inglés) o RED (por sus siglas en español) llegó a experimentar modificaciones significativas para darle una presentación coherente con el requerimiento fundamental de verificaciones a través de procedimientos de auditoría. En contraposición, los desarrollos iniciales llevados a cabo por la empresa MSA con su sistema vot-ar representaron un ejemplo de la necesidad de transitar a una etapa de uso sumamente sencillo de instrumentos de votar, por lo que su diseño de Boleta Única Electrónica (BUE) tuvo la ventaja de que el elector -y los demás interesados en la elección popular- manifestaran su confianza en el sistema al conservar el control visible sobre el destino de las boletas utilizadas y no utilizadas. Sus tempranas ventajas comparativas parecen evidentes en un primer acercamiento, de acuerdo con información en línea de la empresa MSA (http://www.vot-ar.com.ar/es-ar/ventajas/):

Este sistema aprovecha las fortalezas de los sistemas tradicionales basados en la existencia de un documento físico, pero utilizando una Boleta Única Electrónica (BUE). Los votos se registran sobre el papel y en un chip que contiene la boleta. En la máquina no se registra ningún voto ni acción del votante que se haya usado para conformar el mismo. Esto último sumado a la posibilidad de utilizar cualquier máquina del recinto hace que no se pueda rastrear el orden de votación y violar el secreto del voto.

De igual forma que en el sistema tradicional, la primera versión del sistema vot-ar "asegura el contacto físico entre un comprobante o boleta electoral y el elector", con la posibilidad de que "lo electrónicamente grabado en el chip es lo que luego habrá de ser utilizado para realizar el escrutinio, volviendo a controlarse su coincidencia con lo impreso por parte de las autoridades de mesa y fiscales partidarios. Ello implicaba que cualquier persona sin conocimientos técnicos especiales podía verificar el correcto funcionamiento de las máquinas y la conformación de los resultados electorales".

segundos. Así mismo, mostró la posibilidad que se tiene de programar en un sistema de posicionamiento global, GPS, la señal de la máquina en un radio de 25 metros acabando con el voto secreto y que el mismo software puede ser alterado para beneficiar a algún candidato. Además, destacó la facilidad con que tuvieron acceso a los equipos para realizar estas acciones y la poca seguridad con que cuentan los lugares en que se almacenan y trasportan" (Organización Electoral de la RNEC-Colombia, 2014).

${ }^{17}$ No obstante que el sistema DRE fue cuestionado, sobre todo desde las polémicas elecciones presidenciales de los EUA, en 2000, su uso continuó en varios países, por lo menos hasta 2005, conforme a lo que nos dice, por ejemplo, Miguel Ángel Presno Linera (2005: 5): "En el caso brasileño se ha optado por un sistema de los denominados "RED" (Registro Electrónico Directo) o "DRE" (Direct Recording Electronic) en la terminología anglosajona, en el que, en lugar de una papeleta, se dispone de una pantalla o teclado para la emisión del sufragio; el sistema implantado en Bélgica es también de esta naturaleza. En Venezuela, por el contrario, se configuró inicialmente un sistema de los llamados "LOV" (Lectura Óptica del Voto), que no prescinde de la papeleta y que consiste en una urna con lector óptico o escáner que reconoce una papeleta diseñada a propósito y que se introduce manualmente en la urna. La experiencia venezolana con el sistema "LOV" no fue positiva, pues el escrutinio en las elecciones de 1998, en lugar de agilizarse, se prolongó durante meses, por lo que en procesos posteriores se optó por un sistema "RED" que, además, facilita un resguardo o comprobante del voto emitido, y cuyo funcionamiento en el referéndum de agosto de 2004 fue considerado correcto por los observadores internacionales de la Organización de Estados Americanos”. 
Otras de sus ventajas fueron señaladas del siguiente modo, en compatibilidad con lo señalado literalmente por la misma empresa (http://www.vot-ar.com.ar/es-ar/ventajas/) (el autor ha puesto cursivas en algunas de las líneas del texto citado, entrecomillado):

- Almacenamiento externo individualizado y visible versus Almacenamiento interno total y oculto de los votos: "[...] a diferencia de lo que sucede en el sistema tradicional, no hay margen para discusiones respecto a boletas válidas o no. Las BUE son en esencia un voto almacenado en la memoria de la misma en forma electrónica y, además, escrito en forma clara en una de sus caras".

- $\quad$ Escrutinio expedito y eficaz de los votos: "El escrutinio es mucho más rápido que en el sistema tradicional, pero admite la verificación de la asignación de los votos y de la suma de cada uno de ellos".

- Verificación precisa y en todo momento de los votos: "El escrutinio hecho en mesa y fiscalizado por las autoridades de mesa, no sólo arroja resultados precisos, sino que deja en manos de la justicia repetir en forma electrónica el conteo voto por voto, y también si se quisiera, texto por texto".

Luego, entre 2015 y 2019, la presión de los críticos de la BUE -centrada en el riesgo de vulneración por intrusión en la información guardada en el chip- llevó a la empresa MSA y a diversas autoridades electorales argentinas a modificar el modelo original de boleta mediante una regulación que estableció que, una vez que el votante hubiera emitido su voto, al agotarse la secuencia de introducción de la BUE en una máquina con pantalla touch y selección de alguna opción a votar, en el reverso de ella debía aparecer impreso el resultado correspondiente, y que ese debía ser también el documento a considerar en el cómputo de votos emitidos. Así, el chip de un solo dato pasó a un lugar subordinado, mientras la información impresa oxigenó la exigencia general de confiabilidad.

Por su parte, con una denominación similar (Boleta Electrónica) a la de la boleta diseñada por la empresa MSA, y prácticamente "puesto a punto", sólo en espera de una legislación idónea, el prototipo diseñado por el Instituto Federal Electoral (IFE) durante la primera década del siglo XXI supuso el siguiente modo de funcionamiento del sistema, según el Diagnóstico exprofeso elaborado por este organismo electoral en 2010 (IFE, 2010b: 289-290):

Con la propuesta de Boleta Electrónica, [...] [el depósito de la boleta utilizada en la urna tradicional] se sustituye por el almacenamiento del voto emitido por el elector en una memoria electrónica no volátil, en donde a semejanza de la urna actual son almacenados todos los votos emitidos durante la jornada electoral. Aun así, se mantiene un comprobante físico del voto, que permite crear mayor seguridad al elector de que su voto fue registrado y considerado para el cómputo final. Además, constituye un elemento de auditabilidad, permitiendo un posible recuento manual, en su caso, derivado de alguna impugnación.

La Boleta Electrónica integra en un solo sistema la memoria, la impresora y la urna, de manera tal que el voto emitido queda grabado, imprimiéndose además el comprobante que automáticamente cae en un depósito, sin que la mano del elector lo pueda tomar. Este mecanismo garantiza sin duda que el ciudadano no se lleve el comprobante a su casa en lugar de depositarlo, acto que puede suponer una posible coacción o compra del voto.

Con esos dos ejemplos de desarrollo tecnológico en materia de voto electrónico, cada vez más en sintonía con los requerimientos jurídico-electorales, se observa que el diseño de sistemas de voto electrónico puede tener diversas modalidades (véase al respecto el interesante trabajo de Chaparro, 2015: 4-7). Aunque existen diversas modalidades de voto electrónico presencial con comprobación impresa, las referidas aquí para la empresa MSA y el IFE-INE pueden ser consideradas como modelos híbridos de vanguardia que satisfacen exigencias desde el punto de vista de la protección y garantía del derecho del voto, es decir, a efecto de hacer valer la voluntad de los votantes y potenciar la confianza ciudadana. De manera paralela, y para dar cumplimiento a la disposición transitoria de la reforma electoral de 2014 relativa al voto electrónico utilizable por mexicanos residentes en el extranjero, el INE informó en su comunicado de prensa número 066 de 23 de marzo de 2020 que dicha institución "dio inicio, en un acto protocolario, a un simulacro de votación como parte de los trabajos para una eventual implementación del sistema de voto electrónico por Internet, en el que participaron de manera virtual, personal de los 10 Organismos Públicos Locales Electorales (OPLE) cuya legislación contempla el voto desde el extranjero en los procesos electorales 2020-2021 para las gubernaturas de Baja California Sur, Chihuahua, Colima, Guerrero, Michoacán, Nayarit, Querétaro, San Luis Potosí y Zacatecas, así como para una diputación migrante y una de representación proporcional de los estados de Guerrero y Jalisco, respectivamente". Al respecto, el consejero Enrique Andrade, presidente de la Comisión Temporal de Vinculación con Mexicanos Residentes en el Extranjero y Análisis de las Modalidades de su voto, "recordó que el sistema con el que actualmente cuenta el INE para el voto por Internet, fue adquirido a finales del año pasado, lo que ha permitido hacer distintos ejercicios de votación para mostrar este sistema a Institutos Electorales Locales, partidos políticos, diversos actores, así como a medios de comunicación tanto en México como en el extranjero", y que, "en 
general, ha sido un sistema que ha sido bien aceptado, es un sistema seguro, fácil de utilizar y que ha empezado a generar confianza para los distintos usuarios que lo emplearán en 2021". (En línea: https://centralelectoral.ine.mx/2020/03/23/realiza-ine-simulacro-voto-electronico-internet/).

Al respecto, los párrafos 1, 2 y 3 del artículo 329 de la Ley General de Instituciones y Procedimientos Electorales (LGIPE), expedida en 2014 y que entró en vigor una vez abrogado el Código Federal de Instituciones y Procedimientos Electorales (COFIPE), previenen que los mexicanos residentes en el extranjero podrán ejercer su derecho al voto en las elecciones presidencial, de senadores, gubernaturas y jefatura de gobierno de la Ciudad de México, y que podrán emitir su voto mediante boleta impresa o vía electrónica (en formato de "boleta electoral electrónica"). En el primer modo, el voto se envía por correo postal a la sede del INE; en el segundo modo, "el voto por vía electrónica sólo podrá realizarse conforme a los lineamientos que emita el Instituto [...]". El 24 de octubre de 2016, el Consejo General del INE aprobó los LINEAMIENTOS PARA EL DESARROLLO DEL SISTEMA DEL VOTO ELECTRÓNICO POR INTERNET PARA MEXICANOS RESIDENTES EN EL EXTRANJERO, mediante Acuerdo INE/CG770/2016 (véase en línea: https://portalanterior.ine.mx/archivos2/portal/historico/contenido/recursos/IFE-v2/DS/DS-

GacetasElectorales_INE/2016/Gaceta-013/PDF089.pdf.). A su vez, el artículo transitorio Décimo Tercero del Decreto por el que se expidió la LGIPE, publicado en el Diario Oficial de la Federación de 23 de mayo de 2014, establece lo siguiente: "Décimo Tercero. El voto de los mexicanos en el extranjero por vía electrónica se realizará hasta en tanto el Instituto Nacional Electoral haga pública la comprobación del sistema a utilizar para la emisión del voto en dicha modalidad. Para tal efecto, deberá contar con el dictamen de al menos dos empresas de prestigio internacional. Dicho sistema deberá acreditar certeza absoluta y seguridad comprobada, a efecto de garantizar el efectivo ejercicio del derecho al voto de los ciudadanos mexicanos residentes en el extranjero. Para ello, el sistema que establezca el Instituto deberá garantizar, entre otros aspectos: a) Que quien emite el voto, sea el ciudadano mexicano residente en el extranjero, que tiene derecho a hacerlo; b) Que el ciudadano mexicano residente en el extranjero no pueda emitir más de un voto, por la vía electrónica u otra de las previstas en esta Ley; c) Que el sufragio sea libre y secreto, y d) La efectiva emisión, transmisión, recepción y cómputo del voto emitido. En caso de que el Instituto determine la adopción de un sistema para la emisión del voto de los ciudadanos mexicanos residentes en el extranjero, deberá realizar la comprobación a que se refiere el presente transitorio antes de que inicie el proceso electoral del año 2018. De no contar con dicha comprobación para el proceso electoral referido, lo dispuesto en este transitorio será aplicable para los procesos electorales subsecuentes, hasta que se cuente con la comprobación respectiva".

Eficacia y confianza, consecuencias indispensables al voto electrónico

En el caso mexicano, no se puede omitir, por cierto, que el diseño de una regulación-tipo con base en una concepción de principios y derechos político-electorales que requieren ser plenamente protegidos y defendidos, tanto por vía jurídica (por medio de reglas y principios idóneos) como técnica (por medio de máquinas e instrumentos de fácil operación y verificación), permite desprender la respuesta al problema que el informe y el diagnóstico del IFE del 21 de julio de 2010 destacan como limitación para avanzar en la adopción de estos sistemas: la falta de una regulación específica coherente con un tipo de tecnología accesible, que en combinación puedan facilitar la cadena de operaciones de emisión-registro-escrutinio-cómputo de los votos, usar con sencillez los medios e instrumentos de votación electrónica, garantizar el ejercicio de derechos político-electorales y propiciar la confianza en el sistema electoral. Con la creación del Instituto Nacional Electoral (INE) en 2014, los desarrollos del IFE sobre voto electrónico han continuado; sin embargo, es urgente consolidar la prevención de que su implementación requiere de una regulación específica, no solamente apegarse a unas disposiciones transitorias y a unos lineamientos emitidos por una autoridad administrativa que no puede ser sustituta del poder legislativo general.

Puesto que las dos vías de desarrollo de los sistemas de votación electrónica parecen correr más o menos en paralelo, no sobra citar aquí el señalamiento de Marco Antonio Alberto Urday Chávez (2012: 1) que subraya dos objetivos básicos del uso de un sistema de votación electrónica, en cuyo desarrollo cabe considerar necesariamente las ventajas prácticas para el elector y para la institución que organiza las elecciones:

a) "Rapidez en la obtención y publicación de los resultados de la jornada electoral; y"

b) "Sencillez en la ejecución de los procesos de comprobación de la identidad del elector, emisión del voto, conteo de votos y emisión de reportes de resultados".

El vocablo "sencillez", según la acepción número 5 señalada por el Diccionario de la Lengua Española, significa "que no ofrece dificultad". A esto hay que agregar que el neologismo "usabilidad" (no incluido en ese Diccionario y que es la traducción directa de "usability", en inglés), ha sido formulado por la Comisión Europea como parte de una terminología que sustenta nuevas estrategias comunes desde 2005, y significa que, en el marco del diseño de nuevas tecnologías en una 
"sociedad de la información", un producto debe ser "práctico, útil, aprovechable y satisfactorio", pero de modo que el usuario sea "siempre la prioridad" (Vos, 2005: 1 y 2; además, véase Panach Navarrete, 2010). Esta expresión es complementada regularmente con la de "accesibilidad", incluida en el Diccionario invocado, pensando en necesidades comunes de los usuarios, pero con características diversas entendidas como capacidades y limitaciones físicas variadas (véase al respecto, Sáez et al, 2010: 17-23). A su vez, ACE Project, en su sitio web señala como uno de los "requisitos mínimos" del voto electrónico el de "garantizar la accesibilidad al mayor número posible de votantes, especialmente a las personas con discapacidad" (entrada "Requisitos para el voto electrónico" http://aceproject.org/ace-es/focus/fo_evoting/fo_e-voting-requirements). Lorenzo Cotino Hueso (2006: 185) cita el proyecto GOL e-democracy de 2001 para distinguir entre "acceso" y "accesibilidad", y subraya, sin mención de las diferencias de capacidades, que ésta "significa la facilidad con la que uno puede hacer uso real de la posibilidad de acceder a la información electrónica"

El cuadro 1 ilustra esa correlación entre ventajas para los electores y las instituciones, por un lado, y las consecuencias para el sistema electoral en su conjunto, mediada por un par de condiciones previas que tienen que ver con el entramado material e institucional de la implementación del proceso electoral democrático. La correlación debe ser entendida estrictamente en términos de facilitación técnica del proceso de renovación de los órganos de poder, pero también de responsabilización política y de compromiso institucional ${ }^{18}$ (mucho más que un compromiso con el Estado como organización burocrática) en el uso de instrumentos tecnológicos idóneos y del procedimiento específico en votaciones populares y democráticas.

Lo anterior puede ser resumido en los términos que plantea Damián Obremski (2006: 13-14) al referirse a los requisitos básicos del voto electrónico: Desde el punto de vista del elector, son necesarias (a) su confianza en el sistema electoral y (b) su conveniencia para usarlo [...], la cual presenta dicho autor del siguiente modo: "se resume en la facilidad, la comodidad y la sencillez que presente el sistema de emisión del voto electrónico". Pero, desde el punto de vista del propio sistema, como una exigencia que le impone la lógica liberal y democrática de las elecciones populares, Obremski (2006: 14) dice que (el autor de este estudio aplica cursivas en una parte de esta cita textual)

Los sistemas de voto electrónico deben garantizar el anonimato, la privacidad y la no coerción al momento de emitir el sufragio. Es decir, los ciudadanos deben poder votar en total libertad y privacidad, sin que su identidad pueda ser vinculada al voto, respetando así el mandato constitucional. Para ello es necesario mantener separados los padrones de las e-urnas, de manera de garantizar el secreto del voto, aunque estén digitalizados. ${ }^{18}$ Sobre la cuestión del "compromiso institucional" se ha escrito poco, pero mi propuesta es que se trata de un vínculo de los
servidores públicos con el orden jurídico-estatal, más que con la organización burocrática gubernamental-estatal. En ese
sentido, el compromiso institucional es visible para los electores en la medida en que los funcionarios electorales ajustan
plenamente su conducta a los principios, valores y reglas democráticos, y saben que su responsabilización política se
encuentra definida también por su obediencia a los principios y preceptos constitucionales, así como al interés público que se
constituye como contraparte del conflicto entre los intereses particulares. Uno de los trabajos que abordan la cuestión del
"compromiso organizativo", y que ayuda a construir un concepto de "compromiso institucional" es el de Emma Juaneda
Ayensa y Leonor González Menorca (2007: $3590-3609)$. 


\begin{tabular}{|c|c|c|c|}
\hline \multicolumn{4}{|c|}{$\begin{array}{l}\text { Cuadro } 1 \\
\text { Correlaciones entre actores e instituciones con respecto a las condiciones, ventajas y } \\
\text { consecuencias que puede ofrecer el uso de un sistema de votación electrónica }\end{array}$} \\
\hline $\begin{array}{l}\text { Actor } \\
\text { Institución }\end{array}$ & Condiciones & Ventajas & Consecuencias \\
\hline Electores & $\begin{array}{l}\text { Accesibilidad para todo tipo de } \\
\text { electores (incluidos los de } \\
\text { "diversidad funcional") en el } \\
\text { uso de artefactos } \\
\text { infraestructura }\end{array}$ & $\begin{array}{l}\text { Sencillez en la } \\
\text { ejecución } \\
\text { operaciones durante el } \\
\text { ejercicio del derecho a } \\
\text { votar }\end{array}$ & $\begin{array}{l}\text { Confianza en el } \\
\text { sistema electoral }\end{array}$ \\
\hline $\begin{array}{l}\text { Organismo } \\
\text { electoral }\end{array}$ & $\begin{array}{l}\text { Capacidad de la autoridad } \\
\text { electoral administrativa para } \\
\text { implementar los recursos } \\
\text { (humanos, técnicos, jurídicos, } \\
\text { administrativos, tecnológicos y } \\
\text { económico-financieros) del } \\
\text { voto electrónico }\end{array}$ & 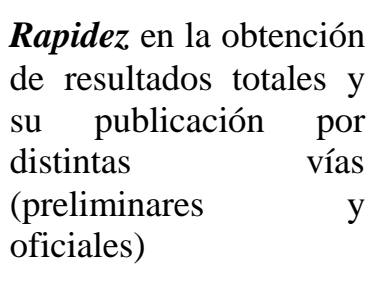 & $\begin{array}{l}\text { Eficacia }^{* 19} \text { del } \\
\text { sistema electoral }\end{array}$ \\
\hline \multicolumn{4}{|c|}{$\begin{array}{l}\text { Fuente: Elaborado por el autor de este trabajo. } \\
\text { * "1.f. Capacidad de lograr el efecto que se desea o se espera" (dixit Diccionario de la Lengua } \\
\text { Española, en línea). }\end{array}$} \\
\hline
\end{tabular}

Los aspectos ineludibles de seguridad / certeza, confiabilidad / confianza

En la literatura existente sobre procesos de votación que utilizan algún tipo de artefacto electrónico, también pueden distinguidos dos grandes grupos de interés:

a) El grupo de estudios clásicos relativos a la incorporación de medios tecnológicamente sofisticados que tiene por objetivo - principalmente- reducir el costo de las elecciones y promover la simplificación de operaciones de emisión y recepción de votos.

b) El grupo de estudios, surgido a finales de la década de 1990, interesado en el marco jurídico aplicable a procesos de votación popular que utilizan tecnologías electrónicas para la emisión-recepción de votos.

En resumen, se trata de investigaciones sobre sistemas de votación electrónica llevada a cabo en dos grandes campos: a) la investigación de tecnologías utilizables en procesos electivos; y b) la investigación normativa interesada en plantear el tipo idóneo de principios, procedimientos y reglas aplicables concretamente durante el proceso electivo. Sin embargo, me parece que hay un aspecto común a los dos campos que no ha sido referido hasta este momento: el de la seguridad. La seguridad informática y la seguridad jurídica revelan la necesidad de que el sistema operativo y las aplicaciones informáticas incorporados en los medios utilizados para emitir y recibir votos estén protegidos de cualquier intrusión y, por tanto, de actos (intencionales o no), circunstancias o factores externos que puedan producir daño o alteración de la información ahí contenida, de modo que ésta pueda ser cierta, confiable y verificable.

\footnotetext{
${ }^{19}$ Karen Marie Mokate (2001) señala que “[...] la eficacia de una política o programa podría entenderse como el grado en que se alcanzan los objetivos propuestos. Un programa es eficaz si logra los objetivos para que se diseñara. Una organización eficaz cumple cabalmente la misión que le da razón de ser". El trabajo de esta autora es relevante para una definición adecuada de "eficacia" en virtud de que, como precedente, dice ella misma, "A lo largo de dieciocho meses en 1997 y 1998, pedimos a diversos grupos de profesionales comprometidos en el diseño y gerencia de políticas y programas sociales definir eficacia, eficiencia, equidad y sostenibilidad. Recopilamos 262 respuestas. De estas, 221 (el $84 \%$ ) han indicado que la eficacia corresponde al cumplimiento de metas y objetivos o a la satisfacción de la necesidad que motivó el diseño y desarrollo de la iniciativa, sin importar los costos y el uso de recursos". Considero que esta misma línea de definición de la eficacia es aplicable al uso de instrumentos y medios de votación electrónica, en tanto que uno de los objetivos institucionales consiste precisamente en reducir los tiempos de las diversas operaciones que se realizan en un procedimiento de votación popular.
} 
Las dudas que se desprenden de la cuestión acerca de la sintonía efectiva -y en un futuro próximo- entre seguridad informática y seguridad jurídica han originado, a su vez, un debate entre quienes pueden ser llamados, por un lado, optimistas y, por otro, pesimistas. Pero, según Jorge Yrivarren (2004), un nuevo enfoque habría surgido en contra de un falso dilema, puesto que la aplicación de medios electrónicos a las votaciones populares es una realidad. Las tecnologías son un medio, no un fin en sí mismo, de modo que su uso debe estar sometido a las necesidades mismas del Estado constitucional democrático y, por tanto, no debe perderse de vista que el ciudadano -como portador de derechos políticos que limitan el poder político-es la prioridad en un modelo democrático.

La emisión de votos a través de dispositivos móviles (teléfonos celulares) denota problemas similares de seguridad informática que en el caso de dispositivos fijos de emisión remota (internet) y de emisión estacional y presencial (urna electrónica y boleta electrónica en sus distintas versiones), pues en todos los casos se exige que la seguridad sea garantizada mediante un proceso de verificación que incorpora métodos específicos de evaluación y técnicas de auditoria, seguimiento, medición, supervisión, verificación, etcétera). En general, la verificación persigue confirmar: a) la autenticidad de los sistemas, el debido funcionamiento de los mecanismos de protección para evitar intrusiones y alteraciones; y b) la capacidad de los propios sistemas informático-y-electoral para generar confianza entre los votantes y a favor de las instituciones.

Según Gamaliel Marín Quebrado y Luis Antonio Gama Moreno, técnicamente la arquitectura de comunicación empleada para llevar a cabo la autentificación de los sistemas informáticos implica un procedimiento (protocolo) de cifrado y descifrado de datos por algoritmos, "a través del uso de una autoridad certificadora (Thawte), para proporcionar integridad, confidencialidad de los datos y autentificación en el protocolo HTTP" o de protocolos de similar función. Así, el objetivo consiste en evitar que los datos que fluyen durante el proceso de petición/respuesta en red "sean fácilmente descifrados o vistos por programas espías conocidos como «sniffers»" (Marín Quebrado y Gama Moreno, 2008). Pero administrativa y jurídicamente, la evaluación de un sistema de votación basado en medios electrónicos requiere conocer si los actores del proceso electoral conforman acuerdos previos (legislación ex profeso, reglamentos, criterios) y acuerdos durante (seguimiento de actos específicos, control de tareas, prevención de fallas, etcétera) que permitan tener la certeza acerca del desarrollo del proceso conforme a las hipótesis legales y los principios jurídicos aplicables. Del mismo modo, Kim Zetter (2008), ocupado de la seguridad y confiabilidad (o fiabilidad) de la votación electrónica, señala lo siguiente:

En 2004, cuando las máquinas de votación de pantalla táctil se distribuyeron ampliamente por primera vez en unas elecciones nacionales de EE.UU., había mucha preocupación por la seguridad y la fiabilidad de las máquinas y, por lo tanto, por la legitimidad de los resultados. Desde entonces, algunos funcionarios electorales han adoptado comprobantes en papel verificados por el votante para mejorar la fiabilidad de los resultados. Sin embargo, cada día se descubren otros agujeros en la seguridad y, de los 32 estados que usan las máquinas de pantalla táctil, solamente 17 requieren que las máquinas produzcan comprobantes de papel.

Esa preocupación ha sido una constante para los estudiosos del tema y los ciudadanos en los distintos Estados de la unión americana que en su mayoría utilizan sistemas de votación electrónica, y ha sido referencia obligada para las principales empresas diseñadoras de máquinas y tecnologías de votación en ese país, a saber: Election Systems \& Software (ES\&S, antes conocida como American Information Systems), Diebold Election Systems y Sequoia Voting Systems; todas ellas obligadas a efectuar modificaciones, actualizaciones e innovaciones sucesivas de sus sistemas para bloquear las intrusiones, aunque se tienen noticias de la aparición de nuevas vulnerabilidades que suelen ser resueltas el mismo día de la votación de una manera poco convencional, a veces a través de asistencia directa a los votantes con boletas impresas de reemplazo emergente. La elección presidencial de 2000 en ese país fue un momento crítico para la Diebold, pues las fallas de sus máquinas se multiplicaron. La Ley HAVA (Ley de Ayude a América a Votar) ${ }^{20}$, aprobada por el Congreso en 2002, que sienta parámetros generales de carácter recomendatorio para los Estados de los EE. UU. en elecciones federales, ha sido una respuesta a esos problemas de los sistemas de votación electrónica, pero no una respuesta total y definitiva. Curiosamente, el gobierno federal y los gobiernos locales comenzaron a impulsar el sistema de votación electrónica remota, por medio de Internet. Así, incluso astronautas estadounidenses que se encontraban en el espacio en noviembre de 2008 pudieron votar en la elección presidencial ${ }^{21}$.

\footnotetext{
${ }^{20}$ HAVA: Help America Vote, por sus siglas en inglés.

${ }^{21}$ Al respecto, se encuentra una nota en la web que relata lo siguiente: En 2008, "los dos astronautas estadounidenses de la Estación Espacial Internacional (ISS), en órbita a $354 \mathrm{~km}$ de la Tierra, votaron en la elección presidencial desde el espacio y alentaron a sus compatriotas a acudir a las urnas, según una transmisión del canal de televisión de la NASA". "La oficina de votación envió luego a los astronautas sus contraseñas y éstos reenviaron las papeletas encriptadas a 46
} 
El estudio de los medios e instrumentos que se utilizan $-\mathrm{o}$ se pueden utilizar- en el procedimiento de emisiónrecepción-escrutinio-cómputo-registro de votos en elecciones democráticas y populares, generalmente ha sido poco atendido. $^{22}$ El estudio que se interesa por los principios y las reglas aplicables a ese tipo de votaciones cuando los medios empleados se modifican, pareciera ser más común; mi opinión es que no lo es tanto y que está estrechamente ligado con el estudio de medios e instrumentos. En realidad, en un proceso de votación hay una estrecha relación entre los medios e instrumentos utilizados, por un lado, y los principios y las reglas que rigen su uso, por otro, a efecto de conseguir una serie de actos jurídicamente válidos.

Ahora bien, la literatura sobre las diversas experiencias de votación electrónica revela que los sistemas aplicados no están "a punto"; hay fallas de funcionamiento de software, incluso de hardware; hay omisiones en el diseño tecnológico, y es que el procedimiento de votación connota "minúsculos" actos, todos importantes, que no pueden ser subestimados; se detectan problemas de funcionamiento técnico de las máquinas, etcétera. Pero, en general, las innovaciones continúan, se adoptan medidas correctivas, se insiste en la aplicación de auditorías informáticas y se previenen cambios para dar transparencia al registro secuencial de los votos y a la constatación informática del historial de cada elección. En compensación, también se ha avanzado -desde la primera década del siglo XXI- en una línea de desarrollo tecnológico que propone una especie de combinación de mecanismos tradicionales de votación con el uso de papeletas o boletas electorales y de mecanismos propiamente electrónicos e informáticos acotados que, por lo tanto, sólo permiten registrar el voto emitido en papel, en el chip de cada boleta y en el sistema de la máquina empleada para la posterior transmisión de resultados finales, sin violar el principio de secrecía del voto. No hay, entonces, un disco interno ni externo de almacenamiento de la información generada que no pueda ser verificada, ni forma de regrabar el chip. La transmisión de resultados correspondientes a una mesa o centro de votación sí se lleva a cabo en red, de igual forma que ocurre con los sistemas de transmisión de resultados preliminares, pero se cuenta con el soporte físico de la compilación de boletas utilizadas y no utilizadas, así como los registros de sumatorias en papel.

En tanto, las incipientes regulaciones apuntan a dos grandes aspectos: a) la institucionalización de sistemas de votación electrónica en pruebas piloto y en aplicaciones selectivas; y b) la procuración de seguridad y certeza en la emisión y registro de votos. Queda pendiente, sin embargo, la etapa de lo contencioso electoral, aunque existen ya algunos casos en los cuales la autoridad jurisdiccional ha intervenido debido a irregularidades denunciadas (como en los Estados Unidos de América) o debido a la carencia de regulaciones explícitas aplicables a votaciones de este tipo (por ejemplo, en Alemania, con el caso conocido por el Tribunal Constitucional Federal de Alemania, en la sentencia con expediente $2 \mathrm{BvC} 3 / 07-2 \mathrm{BvC} 4 / 07)^{23}$. Puede afirmarse, de manera coherente con el propósito planteado al inicio de este trabajo, que las regulaciones jurídicas de los sistemas de votación electrónica son incipientes, a pesar de haber transcurrido varios años desde que fue planteado el desafío en el País Vasco; sin embargo, en el marco de las exigencias del constitucionalismo contemporáneo es urgente satisfacer plenamente la protección y garantía de los derechos políticoelectorales de la ciudadanía.

A pesar de lo anterior, el corporativo español Indra (Indra Soluciones Tecnológicas de la Información e Indra Producción Software), uno de los fabricantes más importantes de sistemas de votación electrónica en el mundo y a la cual el INE adjudicó -en enero de 2020- un contrato trianual por 31.8 millones de pesos para desarrollar el modelo de voto electrónico que funcionará en las elecciones legislativas federales de 2021, concretamente para los votantes mexicanos residentes en el extranjero, ha estado interesada desde hace varios años en reducir tanto las desventajas técnicas de operación como la necesidad de modificar la legislación electoral. Por ejemplo, para Juan Navarro, cuando

través del centro de control de la agencia espacial. «Nadie puede tener acceso a sus papeletas», explicó Jennifer Ballard, responsable electoral del condado de Harris (Texas). La primera vez que un astronauta estadounidense votó desde el espacio fue en 1997, desde la antigua estación espacial rusa Mir [gracias a una ley votada por los legisladores del Estado de Texas en 1997". Véase la nota de AFP en la edición digital de El Deber, 4 de noviembre de 2008, http://www.eldeber.com.bo/2008/2008-11-04/vernotaahora.php?id=081104155116, y la nota publicada en inglés, también de AFP, el 31 de octubre de 2008, en http://afp.google.com/article/ALeqM5jE_Y_pYLFeaN-yutYT2L3L8QDHQ De ese hecho hay video corto en http://www.telegraph.co.uk/news/newstopics/uselection2008/3273456/USelection-2008-Astronauts-cast-presidential-votes-from-space.html

${ }^{22}$ Con el afán de simplificar la escritura a emplear sugiero denominar a dicho procedimiento de emisión-recepciónescrutinio-cómputo-registro de votos procedimiento global de votación. Así, un voto emitido en un sentido determinado cuenta y debe contar en el mismo sentido durante todo el procedimiento y su existencia debe ser verificada.

${ }^{23}$ Véase la sentencia referida localizada a través del link: https://blog.smaldone.com.ar/files/evoto/fallo_alemania.pdf. La sentencia está traducida al español por Manfredo Koessl y comentada por José M. Pérez Corti. 
fungía como Director de Procesos Electorales de Indra, el desarrollo de urnas electrónicas "se ha concebido para automatizar el escrutinio electoral sin tener que cambiar la ley electoral. Aunque puede avanzarse hasta donde se quiera, el punto de partida se ha hecho con la idea de respetar la legislación vigente". ${ }^{24}$ Esta es una alternativa pragmática de uso de medios de votación electrónica que apunta, por tanto, a adaptar la disponibilidad tecnológica a las exigencias normativas que no contienen normas específicas en esa materia. Pero la alternativa no es la más idónea desde el punto de vista constitucionalista de máxima protección y garantía de derechos político-electorales.

En cuanto a la necesidad tecnológica y la necesidad normativa, Jordi Barrat Esteve dice lo siguiente: "el primer interrogante que deberíamos solventar consiste en saber si realmente es necesario que los actuales sistemas electorales modifiquen su estructura e incorporen las últimas novedades técnicas. La respuesta no debe basarse en un ingenuo optimismo tecnológico ya que tal actitud nos arrastraría fácilmente a un escenario en el que la técnica se convertiría en un fin en sí misma cuando, en realidad, los objetivos y prioridades de cualquier modelo electoral deben ser otros". Y por cuanto a la faceta regulativa, "la regulación electoral deberá, en definitiva, cambiarse solamente si conseguimos demostrar que las nuevas herramientas son útiles para mejorar la expresión de la voluntad popular e incentivar los canales de participación ciudadana" (Barrat Esteve, 2004). Este enfoque es mesurado por cuanto parece que en materia de sistemas de votación electrónica se manifiesta un contraste entre aquellos que trabajan para incorporar rápidamente los sistemas de votación electrónica, principalmente desde las empresas que dominan el mercado tecnológico (Diebold, Indra, Excelsis, SmartMatic, Sequoia Voting Systems, Corporación Electrónica de India, Bharat Electronics Limited, etcétera), y aquellos que pretenden contener la inseguridad informática por medio de regulaciones severas o, en su caso, de políticas tradicionalistas que pregonan la ventaja de la visibilidad del papel y el lápiz, así como de la urna transparente para el depósito de boletas utilizadas por los votantes.

En efecto, antes de sentirnos fascinados por las tecnologías, cualquiera que sea su desarrollo, tenemos que preguntarnos sobre los fines que persigue todo procedimiento de votación fincado en los principios que - por ejemplo, en México- rigen el ejercicio del sufragio-voto: universalidad (cero exclusión, cero discriminación), libertad (plena autonomía del ciudadano para ejercer sus derechos), secrecía (cada votante sabe el sentido de su voluntad, y sólo él) y emisión directa (prohibición de intermediarios). En definitiva, y como extensión de las cuestiones ya planteadas arriba: ¿Qué es lo que debe protegerse? ¿Qué debe desarrollarse con prioridad? ¿Deben adecuarse los medios a los fines, los fines a los medios o ambas cosas bidireccionalmente? La cuestión también es de cultura política democrática, y eso no implica -para la ciudadanía- precisamente sólo un aprendizaje mecánico, de simple secuencialidad de pasos, sino ante todo, en primer lugar, un proceso de modificación de condiciones socioculturales de manifestación de la voluntad ciudadana y, en segundo lugar, la convicción de que un determinado tipo de instituciones (incluidas las reglas y los principios jurídicos aplicables) en un régimen político es coherente con la lógica del Estado constitucional y democrático.

Por tanto, se trata de indagar qué tipo de condiciones (técnicas, operativas, legales, etcétera) son propicias a los principios que rigen un procedimiento de votación en un modelo de democracia representativa, así como a los fines de la voluntad popular en un acto específico y transcendental. Como bien afirma Jorge Yrivarren (2004: 122), "la implantación a la totalidad del electorado de un sistema de votación electrónica, como hasta aquí se ha definido, requiere de una solución tecnológica", además de "normatividad legal, alfabetización tecnológica, infraestructura tecnológica y compromiso de los actores", de manera "progresiva e incremental". Pero el gran problema (o problema matriz) consiste precisamente en encontrar el justo equilibrio entre el extremo tecnológico y el extremo normativo, de manera que no tengamos manifestaciones de fenómeno alguno de ludismo en la etapa madura de la era informática. ${ }^{25}$ Incluso se puede advertir el dilema al que se pueden enfrentar los consultores y los tomadores de decisión a la hora de hacer un balance adecuado entre el uso de nuevas tecnologías y el diseño de nuevas normas jurídico-electorales, porque hay una tensión entre el determinismo tecnológico (que da preferencia al cambio a partir de la incorporación generalizada de mejoras tecnológicas) y el determinismo jurídico (que da preferencia al imperio de la ley). ${ }^{26}$

24 Nota periodística publicada en la red mundial, el 4 de abril de 2001, y consultada en http://www.computing.es/Contenido.aspx?ContenidoId=200104030003

25 "Numerosas rebeliones lideradas por Ned Ludd (de ahí el nombre del movimiento ludista) se desarrollaron desde la década de los 60 del siglo XVIII; muchas fábricas fueron incendiadas o destruidas en diversas ciudades industriales de Inglaterra, pero en tanto se trataba de un movimiento equivocado de protesta, sin ninguna proyección, sus autores fueron perseguidos y puestos fuera de la ley" (véase Pedro Jarrín, 2006: 87).

${ }^{26}$ Véase al respecto el excelente trabajo de Carlos Eduardo Valderrama H. (2012) sobre la "reducción tecnológica" (una manifestación del determinismo tecnológico) y las resistencias sociales, a partir de la consideración de que todo cambio que se impone socialmente tiene su origen en la función de hegemonía a través del Estado. 
Sin duda, hay demasiada información en periódicos, libros, revistas e informes, que da cuenta de que el uso de medios electrónicos en votaciones populares ha sido cuestionado por diversas razones, diferentes circunstancias y distintos momentos. Son ejemplo de ello: la polémica elección presidencial estadounidense, el martes 7 de noviembre de 2000, principalmente por problemas de cómputo de votos en el Estado de Florida, con el uso del sistema de tarjetas perforadas; y el temprano abandono oficial del voto electrónico en Holanda, el 16 de mayo de 2008, 23 años después de haber adoptado una legislación al respecto y luego de que, en 2006, un grupo de ciudadanos (autodenominado "We don't trust voting computers", "No confiamos en equipos de votación") evidenció la vulnerabilidad del sistema empleado (véase este dato de la ONPE vía http://wsr.registraduria.gov.co/Holanda-pionero-en-la.html). Desde entonces y hasta 2016, Holanda conservó un sistema electoral mixto con instrumentos convencionales y electrónicos. Al inicio de febrero de 2017, el gobierno holandés anunció oficialmente el abandono del "software utilizado para contar y trasmitir los resultados de electorales luego de diversos informes que indicaban que el programa había quedado desactualizado, lo que lo hacía vulnerable a hackeos" (texto de la nota en el sitio de INFOTECHNOLOGY fechada el 2 de febrero de 2017: http://www.infotechnology.com/online/Holanda-abandona-el-voto-electronico-y-vuelve-al-conteomanual-20170202-0002.html). Para las elecciones parlamentarias, municipales y regionales del 15 de marzo de 2017, Holanda utilizó solamente el sistema convencional de cómputo manual de los votos. Al parecer, una de las razones por la cual el gobierno decidió abandonar de una vez por todas el sistema electrónico de votación fue el temor a que informáticos rusos pudieran hackearlo, como se presume que pudo ocurrir del mismo modo en la elección presidencial de los EE.UU. de la que resultó ganador Donald Trump. ${ }^{27}$

Del mismo modo, desde hace algunos años, al inicio del siglo XXI, cada vez más se levantan voces que cuestionan la confiabilidad de los sistemas empleados en Brasil (en 1990 comenzó el estudio y en 1998 se implementó el sistema de modo vinculante), Venezuela (en 1998 comenzó a experimentar y en 2004 lo adoptó oficialmente) e India (implementado oficialmente desde 1998), en donde las elecciones se realizan al 100\% con sistemas electrónicos. En las elecciones municipales de 2016 en Brasil, como lo tenía previsto el Tribunal Superior Electoral desde 2015, se emplearon alrededor de 450 mil máquinas electrónicas de votar y no se utilizó otro sistema de votación, a pesar del riesgo de regresar al sistema convencional de papeletas por problemas presupuestales avizorados desde finales de 2015.

Al respecto, puede ser referida la afirmación de Julio Téllez Valdés (2012: 283) relativa a que todo tipo de sistemas electorales es susceptible de experimentar errores, sea o no con el uso de medios electrónicos, por lo que su observación puede ser exagerada "si se solicita que cualquiera deba poder comprender la totalidad del hecho electoral", incluyendo la preparación técnica del proceso electoral, y que incluso la integración de autoridades electorales y las "versiones de equipos electorales" queden bajo control público. Lo cierto es que crece el número de expertos escépticos del uso de sistemas electrónicos de votación, incluido el fundador de Microsoft, Bill Gates, quien en 2015 afirmó que "para lo último que se debe utilizar informática es para unas elecciones", porque los diseñadores de esos sistemas y quienes los implementan pueden prestarse a usos tramposos (http://www.lanacion.com.py/2015/04/05/urnaselectronicas-no-son-confiables-segun-bill-gates/). Y esta polarización de opiniones también vale la pena señalarla como una constante en el mundo de los sistemas de votación electrónica, porque se ha convertido en un parámetro relevante para balancear las ventajas/desventajas de los sistemas electrónicos en elecciones populares.

De ese tipo de advertencias se puede señalar, por cierto, la formación de dos grupos en torno al uso de medios electrónicos en elecciones populares: unos confían en estos medios debido a las ventajas técnico-administrativasfinancieras que ofrecen, pero otros desconfían porque no se satisfacen las exigencias de una serie de principios que rigen ese tipo de elecciones para garantizar de manera efectiva el voto popular. A su vez, esta desconfianza es entendida por Gerardo Irimia (2004: 36) del siguiente modo:

Todos los actores del proceso electoral en su momento manifiestan temor por la adopción de nuevas tecnologías. Los funcionarios públicos temen por una reducción de la fuerza laboral, las elecciones por su naturaleza son políticamente sensibles por lo que puede existir también una oposición política al cambio, el electorado también resiente el cambio tecnológico al dudar que su intención de voto no sea respetada.

Ahora bien, en los procesos electorales -sea por medios tradicionales o por medios tecnológicamente sofisticados - el votante ha sido parte fundamental de la democracia del mismo modo que, como sostiene Fernando Barrientos del Monte (2004: 3): "el voto es el corazón de la democracia procedimental". Así, "la emisión del voto, aun en su sencillez,

\footnotetext{
${ }^{27} \mathrm{Al}$ respecto, véase la nota publicada en esa fecha en línea: http://www.eluniversal.com.mx/articulo/mundo/2017/03/15/holanda-vota-en-eleccion-clave-para-su-futuro-y-el-deeuropa. Además, la nota de PressReader publicada por La Vanguardia el 6 de febrero de 2017 en línea: https://www.pressreader.com/spain/la-vanguardia/20170206/281883003077360).
} 
guarda una importancia fundamental ya que es la expresión formal de los intereses de una sociedad y genera gran parte de la legitimidad que mantiene la estabilidad en los sistemas políticos democráticos. Por medio de su ejercicio se eligen los representantes de la sociedad en el gobierno".

Lo anterior da la pauta para señalar que el problema que deriva del uso de tecnologías informáticas en el procedimiento global de votación (en elecciones populares) consiste en lo siguiente: en primer lugar, el elector requiere tener certeza de que en el procedimiento de votación no hay ocultamiento de datos comunes, y que lo único que no está ni puede estar a la vista de los demás es el sentido del voto de cada cual, más precisamente la correlación entre quién decide y la opción por la que decide; en segundo lugar, el elector debe quedar convencido de que su voto será respetado sucesivamente en el mismo sentido que lo emitió (aunque no hay forma de probarlo individualmente, uno a uno), por lo cual el uso de cualquier medio o instrumento de emisión-recepción-recuento de votos debe garantizar la seguridad, confiabilidad y transparencia del procedimiento y, por tanto, del modo como se manifiesta la voluntad del cuerpo electoral. ${ }^{28}$

Conforme a lo anterior, toda elección que se basa en un ejercicio libre de derechos, así como en la tutela de los mismos, debe resultar auténtica. Esto significa, en general, que toda elección democrática se realiza sólo conforme a reglas, procedimientos y principios comunes o generales que garantizan un ejercicio igual de derechos político-electorales. Por tanto, la aplicación de reglas o procedimientos de excepción dirigidos a un sector del conjunto de ciudadanos, para un mismo tipo de actos electorales y un mismo proceso, es incompatible con principios jurídicos democráticos, puesto que producen situaciones de privilegio o una desigualdad en la distribución de cargas y estímulos.

Consecuentemente, planteo la cuestión acerca de la susceptibilidad de un sistema de votación electrónica a ser evaluado con el objeto de proveer de elementos que garanticen esos principios en las distintas etapas del proceso electoral y, desde luego, el ejercicio libre de derechos. Dicha evaluación -estrechamente ligada con el concepto de auditoría - debe ser entendida en sentido amplio o fuerte: como un método que permite determinar la idoneidad y pertinencia de un tipo de medios (técnicas, recursos, tecnologías, acciones) para la realización de objetivos y fines preestablecidos, en los distintos momentos (ex ante, durante y ex post) del proceso de que se trate, ${ }^{29}$ todo lo cual permite a la autoridad competente calificar una elección y cada uno de los actos que la componen en términos de validez o, al contrario, invalidez.

En ese sentido es que planteo incorporar en la norma jurídica la posibilidad de aplicar programas de auditoría a los sistemas de votación electrónica, no sólo a la configuración y operación de los medios físicos de emisión de votos. El propósito de ese tipo de auditorías consiste en verificar la autenticidad de la votación o elección, un principio democrático que recogen las Constituciones políticas democráticas y por el cual se busca garantizar que todo voto emitido conserve sus características y mantenga la intención del elector o, en sentido negativo, que no sea objeto de alteración de orden físico o jurídico. Sin embargo, cabe plantearse la misma pregunta que se formuló Pedro Antonio Dourado de Rezende, académico de la Universidad de Brasilia: “¿Cuán posible es definir lo que es posible de auditoría en estos nuevos procesos electorales electrónicos? De una forma más precisa, se trata de la pertinencia o de la necesidad - o no- de poder retener una representación física/tangible (impresión en papel) de cada voto efectuado en el sistema, con la posibilidad de permitir la fiscalización del escrutinio de votos hecho manualmente" (Dourado de Rezende, 2007).

Del mismo modo, los conceptos de "permanencia jurídica” y "alteración jurídica" son básicos en el Derecho, pues permiten comprender la integridad o autenticidad de los actos jurídicos. Igualmente, en votaciones populares y democráticas, el principio de conservación de los actos jurídicos rige con la finalidad de mantener la unicidad y la intención de la voluntad del cuerpo electoral, por un lado, y de anular aquellos actos contrarios a ésta, por otro. Por tanto, bajo dicho principio se pretende proteger que los actos jurídicamente válidos en una elección -generalmente asociados al ejercicio de derechos fundamentales- produzcan los efectos jurídicos esperados en todo Estado constitucional y democrático. ${ }^{30}$

\footnotetext{
${ }^{28}$ Sobre el concepto de cuerpo electoral y su significado en el marco de la doctrina francesa de la soberanía conforme al principio de prohibición del mandato imperativo, véase Raymond Carré del Malberg (2001).

${ }^{29}$ Dos trabajos fueron utilizados en este estudio para dilucidar el significado de evaluación, estrechamente ligado con el de auditoría: el libro de José María Aguilar Idáñes y Ezequiel Ander-Egg (1992) y el de Myriam Irma Cardozo Brum (2006).

${ }^{30}$ Sobre el principio de conservación de los actos aplicado a elecciones, véase el trabajo de Enrique Álvarez Conde (1991: 16-17). Según este autor, el referido principio consiste no sólo en el ejercicio de derechos fundamentales, sino
} 50 
Queda claro que uno de los principios jurídicos que permite la previsión de reglas que faciliten el control público de los procedimientos de auditoría de los medios utilizados en la emisión-recepción-cómputo de votos, como forma concreta de la verificación prevista, es el principio de máxima publicidad. Para el caso mexicano, por primera vez este principio está incluido en el artículo 41 de la CPEUM, gracias al decreto de reforma constitucional en materia electoral publicado en el DOF de 10 de febrero de 2014, y es probable que su inclusión ayude a reforzar la labor interpretativa de la autoridad jurisdiccional en situaciones de conflicto.

Respecto a la cuestión de la seguridad, es pertinente señalar que la concatenación de dos niveles de verificación (que incluyen una diversidad de mecanismos de monitoreo, seguimiento, medición y control) dan la pauta para construir un ambiente de confiabilidad en el uso de medios electrónicos de votación. Al respecto, Pedro Antonio Dourado de Rezende (2007) sugiere tratar la cuestión de la seguridad en dos sentidos: el de la seguridad del elector y el de la seguridad de la autoridad organizadora del proceso electoral. Esos dos sentidos son formulados por él del modo siguiente:

Primer sentido: El de la seguridad de los votantes y la transparencia del pleito, contra eventuales manipulaciones indebidas del proceso de cualquier origen o forma de alteración/invasión del sistema, a través del cual estas manipulaciones pueden ser detectadas por medio de un control y fiscalización efectivos. Este primer sentido tiene que ver con la garantía de los derechos fundamentales de carácter político-electoral.

Segundo sentido: El de la seguridad de los organizadores o ejecutores del proceso con derecho al acceso del sistema para programarlo, controlarlo $y / u$ operarlo, contra eventuales detecciones por fiscalización/comprobación, de cualquier desliz por incapacidad (=inepcia) y/o mala intención, a través de los cuales se puede configurar el riesgo de la transparencia del pleito. Este segundo sentido tiene que ver con la garantía de la función electoral adjudicada a un tipo específico de autoridades.

Se advertirá, en lo sucesivo, que la cuestión de la seguridad jurídica -que algunos autores tratan como un principio jurídico de orden "ideológico" 31 - se encuentra estrechamente asociado al parámetro de seguridad informática tratándose del uso de medios electrónicos o informáticos en procedimientos electorales.

A la fecha, y salvo los casos verdaderamente pioneros en materia de elecciones por medios "electrónicos" (Holanda, en 1965; y Bélgica, en 1989) 32 o mecánicos y luego electrónicos (los Estados Unidos de América, en 1892) los estudios sobre voto electrónico o votación electrónica se habían centrado en una primera etapa (años de 1980 a 1995), en primer lugar, en la posibilidad de incorporar tecnologías informáticas a los procesos electorales nacionales o locales, con el propósito de reducir los tiempos de emisión y recuento de votos y de generar resultados oficiales con oportunidad; en segundo lugar, en la posibilidad de reducir el riesgo de fraude electoral causado por la manipulación ilícita de boletas de papel y el recuento erróneo de los votos en el lugar de la votación. No hay que olvidar, por cierto, que, al crear sus respectivas máquinas de votar, tanto Thomas Alva Edison (en 1868) como Jacob H. Myers (en 1892), por petición del Congreso estadounidense, se les hizo saber que ello debería tener como finalidad combatir el fraude electoral, una

"también por otros concurrentes criterios hermenéuticos" [...] "en orden a los derechos fundamentales, como es el de la necesaria proporcionalidad entre unos actos y sus consecuencias cuando estas afectan a derechos fundamentales".

${ }^{31}$ Según Mark Van Hoecke (1996: 425), algunos de los principios jurídicos ideológicos no cuentan con apoyo institucional o estructural y, por tanto, son estrictamente "ideológicos" por cuanto sólo "resultan de la aplicación -por los tribunales- de valores o normas no jurídicos. Entre esos principios se encuentran los de "seguridad jurídica", "razonabilidad" y "prohibición del abuso de derecho". Otro autor, Robert Summers (2002: 37-59), propone una clasificación variada de los principios del Estado de derecho conforme a criterios relativos a su naturaleza, sus funciones generales y los fines y valores a los que sirven.

${ }^{32}$ Holanda es considerado pionero en la previsión legislativa de elecciones "electrónicas", desde 1965, aunque fue hasta 2004 que realizó elecciones por urna electrónica para renovar el Parlamento Europeo. "La legislación electoral permite el uso del voto electrónico desde 1965, mediante el sistema de tablero electrónico con pantalla no táctil" (Véase al respecto el documento de difusión sobre "Voto electrónico" publicado en http://www.euskadi.net/botoelek/otros_paises/sim0_c.htm). Pero, en sentido estricto, Bélgica es pionero en el continente europeo en el uso de sistemas de votación electrónica, con el uso de pantalla de opciones y lápiz óptico para su selección, desde la prueba piloto realizada en 1991, dos años después de haber previsto normativamente esta posibilidad. Sin embargo, como se señala en ese documento citado en la presente nota, "El primer uso oficial de una máquina de votar (conocida como cabina automática de votar -"Myers Automatic Booth"-) se desarrolló en New York in 1892. Hacia 1930, estas máquinas estaban instaladas en las principales ciudades de Estados Unidos y en 1960 más de la mitad de la población votaba usando estas máquinas", http://www.euskadi.net/botoelek/otros_paises/sim0_c.htm\#EstadosUnidos. 
práctica decimonónica común en algunos países (incluido México) que se veía reflejada en la alteración de la cantidad y del sentido de los votos.

Justamente cuando se inició la revolución de las tecnologías informáticas con el ingreso del sistema operativo Windows en su versión Windows 95, lanzado por Microsoft como complemento superior del Disk Operating System (DOS), lo cual coincidió con la diseminación de computadoras de uso personal (véase García Camarero, 2009), a partir de 1995, se ingresó a una segunda etapa en la cual se comenzó a discutir lo mismo acerca del uso generalizado de sistemas de votación electrónica en algunos países (Brasil, Venezuela) que de las frecuentes fallas de esos sistemas en países con cierta tradición en la materia (los Estados Unidos de América, Holanda, etcétera) y del posible retorno a procedimientos y medios tradicionales de votación. Pese a esa paradoja, varios gobiernos, organismos electorales y organizaciones interesadas en resolver problemas de eficiencia (económica, administrativa y tecnológica), participación electoral y seguridad informática, han estado trabajando en diversos proyectos de mejora del diseño (arquitectura de software y hardware) de las máquinas de votación electrónica, de reducción del costo económico por unidad/periodo de vida de dichas máquinas y de habituación a las nuevas tecnologías mediante "pruebas piloto". Si bien en algunos lugares del mundo la cuestión de la "nueva legislación" ya se resolvió relativamente (Brasil, EUA, Venezuela, Euskadi) o comienza a ser abordada como un tema relevante para conseguir el éxito de las votaciones electrónicas, en general continúa siendo una cuestión a debate.

En el caso particular de México, se balbucea un cierto interés de los partidos políticos por incorporar nuevas tecnologías en los procesos electorales, concretamente para la emisión del voto, y se llevan a cabo algunas "pruebas piloto" para mostrar públicamente las virtudes de los sistemas de votación electrónica, además de iniciar a los ciudadanos en un nuevo episodio de la historia de las elecciones. De manera implícita o a veces explícita, en los desarrollos tecnológico-electorales se señala el problema de falta de sincronía entre la seguridad informática que requiere un sistema virtual para operar eficazmente y la seguridad jurídica que requiere todo proceso electoral para ofrecer resultados efectivos dentro de los plazos fatales establecidos legal o constitucionalmente. Así, si la máquina de votar que aplica un sistema electrónico tiene un rango de error aceptable técnicamente en su operación (que puede ser subsanado el mismo día de la votación) y unas características apropiadas para blindar el sistema de toda posible intrusión y alteración de datos, dicho problema tenderá a diluirse políticamente, con la probable consecuencia de una menor propensión a recurrir los actos y omisiones de la autoridad electoral.

Estándares y principios exigibles a la regulación del voto electrónico

Sobre la pertinencia de una diversidad de normas internacionales en materia electoral, la Comisión Europea (2013: 9) señala que:

Cualquier persona que tenga interés en la calidad de un proceso electoral debe consultar las normas internacionales. Aquí se incluyen: parlamentarios, legisladores, administradores electorales, las personas que llevan a cabo la asistencia técnica del proceso electoral, observadores, candidatos y partidos internacionales y nacionales, organizaciones de la sociedad civil, así como cualquier otra parte interesada o analista. Las normas internacionales proporcionan a las personas interesadas en unas elecciones una herramienta de análisis del proceso de acuerdo con los criterios acordados para las elecciones auténticas.

Ese documento de la Comisión Europa, sin embargo, en su sección introductoria también previene acerca de las particularidades de cada país con relación a "factores técnicos, políticos y sociales", por lo que, si bien las normas internacionales pueden ofrecer alguna solución al diseño de sistemas electorales nacionales, por cuanto a principios y derechos reconocidos en instrumentos internacionales (vinculantes y no vinculantes), también es cierto que para cada caso deben ser tomados en cuenta los factores y las necesidades internas. Esto no obsta para que cada Estado atienda las normas a las que queda obligado al haberse adherido a alguno de esos instrumentos.

Ahora bien, como he insistido, los sistemas de votación electrónica requieren cumplir - de entrada- con los principios de seguridad y certeza en mayor grado que los sistemas convencionales, pero, de acuerdo con Porras Robles (2012: 5) aquellos no tienen resuelto el problema de seguridad por vía técnico-informática y, del mismo modo, tampoco por vía jurídica. La seguridad técnica debe satisfacerse al cien por ciento y eso significa que cada voto emitido por ese medio debe contar igual que los demás, diferenciándose sólo con relación a las opciones preferidas. Así, este autor sostiene lo siguiente en la misma página referida:

Un sistema de votación electrónica requiere cumplir con variados requerimientos de seguridad, como, por ejemplo: asegurar la privacidad de los votos, evitar que los votos sean alterables, garantizar que el recuento de los votos sea realizado sin errores, que ningún voto válidamente emitido sea ignorado durante el conteo de los votos, y que el 
proceso de votación sea auditable o verificable por agentes externos a la votación o por los mismos votantes. La criptografía se ha utilizado durante los últimos años para satisfacer este tipo de requerimientos en muy diversas áreas de la computación, por lo que, para satisfacer los requisitos de un sistema de votación electrónica, se hace indispensable la utilización de diversas herramientas y protocolos criptográficos ya conocidos. Por ejemplo, algunas de estas herramientas son: criptografía simétrica y criptografía de clave pública, encriptación y desencriptación de datos, firma digital y verificación, hashing y huellas digitales, y esquemas de compartición de secretos.

En materia de criptografía -y más en la combinación de diversas herramientas y protocolos de seguridad- se ha avanzado mucho, pero su implementación no está resuelta, agrega Porras Robles. Una cosa es que el esquema criptográfico sea correcto para diseñar un sistema de votación, pero otra cosa es cómo el sistema empleado y sus operadores podrían enfrentar problemas a los que todo sistema de votación está expuesto cuando funcionan a gran escala (Porras Robles, 2012: 6). Y aquí vienen las exigencias técnicas que, a su vez, al cumplirse, pueden satisfacer las exigencias de tipo jurídico-político, según este mismo autor (2012: 6-8). Se trata de una serie de condiciones técnicas -pero no desconectadas de las condiciones jurídico-políticas- que son necesarias y ofrecen distintas ventajas, a saber:

- $\quad$ El sistema debe ser capaz de recuperarse a tiempo de fallas propias y de aquellas provocadas en su entorno, "sin pérdida de la información o de votos emitidos por los votantes".

- "El sistema debe ser auditable o verificable tanto en su implementación como en su funcionamiento" a fin de "dar confianza a los usuarios".

- La implementación del sistema debe conllevar reducción de costos y facilidad para corregir errores, y su "proceso de instalación y administración" "debe ser lo más automatizado posible limitando la necesidad de interacción humana en su funcionamiento".

- $\quad$ "El sistema debe usar formatos de datos estándares y abiertos que puedan ser revisados externamente al sistema antes, durante o después del proceso de elección".

- El software utilizado debe ser certificado y no debe ser modificado ni reemplazado.

- La administración de la elección debe estar compartida o distribuida entre diversos funcionarios, para evitar la concentración del riesgo de manipulación de la elección, pero el acceso al sistema debe ser limitado y operar en un entorno de red protegido para evitar ataques de denegación de servicios o la suplantación de servidores o usuarios.

- El acceso del usuario al sistema debe ser simple y fácil de aprender por los ciudadanos, a fin de evitar un tipo de restricción al ejercicio del derecho a votar.

- $\quad \mathrm{Y}$, ante todo, para efectos de este estudio, importa mucho que la seguridad técnica no se obtenga como "seguridad por oscuridad", sino derivada de una implementación "abierta al escrutinio e inspección pública en busca de errores o vulnerabilidad de seguridad".

Al respecto, cabe concatenar aquí la siguiente reflexión de Miguel Ángel Presno Linera (2007 2):

La eventual introducción legislativa del voto electrónico está supeditada al respeto de los elementos que constitucionalmente configuran el sufragio como libertad subjetiva, pero, por otra parte, la dimensión objetiva de este derecho convierte en un "mandato de optimización" dicha introducción, si con ella se favorece su ejercicio, pues esa dimensión requiere de los poderes públicos y, en particular del Legislador, actuaciones concretas que permitan el máximo desarrollo, jurídico y práctico, del haz de facultades comprendido en este derecho fundamental.

Para el caso mexicano, puesto que hoy en día la salvaguarda efectiva de los derechos humanos -que incluyen a los de naturaleza político-electoral- se funda en una serie de principios que justifican la propia expansión de la interpretación normativa, en el marco de unidad del derecho interno y el derecho internacional, y particularmente porque la reforma constitucional en materia de derechos humanos, aprobada en 2011, consolidó dicha unidad, cabe señalar además la importancia de que la autoridad jurisdiccional extreme las garantías necesarias para la realización efectiva de la voluntad popular cuando se utilicen medios electrónicos de votación. No sobra decir, por tanto, que los principios de interpretación conforme y pro-persona (o pro homine), que se encuentran establecidos expresamente desde esa fecha en el artículo $1^{\circ}$ de la Constitución Política de los Estados Unidos Mexicanos, son cardinales para la expansión posible del derecho a votar, en términos de una protección efectiva del cuerpo electoral por el derecho unificado.

Del mismo modo, cabe señalar de paso que una arquitectura física agradable de las máquinas de votación electrónica, una arquitectura de sistemas ${ }^{33}$ eficiente y sólida, además de un software para la operación sencilla del sistema y desde ${ }^{33}$ Una definición usual de "arquitectura de sistemas" (o "estructura del sistema"), como "sistema de información", es la
siguiente: "Es la organización fundamental de un sistema, que incluye sus componentes, las relaciones entre sí y el
53 
el usuario y, por tanto, para facilitar su uso y dar seguridad a su funcionamiento, sin intrusión ni alteración alguna, configuran un conjunto básico de condiciones técnicas -incluso estéticas- significativas para hacer efectivos los principios y las reglas aplicables a los procesos de elección popular democrática. Este ambiente técnico e informático es significativo para un proceso electoral que requiere garantizar el ejercicio de derechos político-electorales de los ciudadanos. Así, el medio se subordina al fin; pero, inversamente, la búsqueda del fin -que en sí mismo es jurídicamente necesario- debe procurar el mejor medio técnicamente posible.

Subrayo que se trata de un conjunto básico de condiciones significativas, pero no única ni fundamentalmente. Otras condiciones - de tipo legal, cultural, político y social- concurren en un proceso electoral, las cuales no están asociadas directamente con las características técnicas de los medios utilizados en la emisión-recepción-escrutinio-cómputopublicación de resultados, pero son necesarias para:

- $\quad$ Permitir la verificación de operaciones y resultados in situ y ex post.

- Dar certeza y autenticidad a los actos desarrollados y los resultados;

- Hacer confiable y transparente el proceso en general;

- Propiciar la confianza en los sistemas de votación electrónica mediante la aplicación estricta del principio de máxima publicidad de los actos de autoridad y de toda la función electoral;

- $\quad$ Mantener en secrecía la voluntad del votante con respecto al sentido de su voto; y

- Dar seguridad jurídica de que el proceso electoral transcurre conforme al marco del Estado constitucional y democrático, y de que, en su caso, éste podrá ser restituido.

En esa trayectoria, Fernando Tuesta Soldevilla (2004: 67) señala que un sistema de voto electrónico debe garantizar tres cosas relativas a:

i) la confiabilidad para conservar el principio de secrecía del voto;

ii) la seguridad informática ante posibles ataques externos (protección programada ante intrusiones, fallos del software o manipulación errónea del administrador del sistema); y

iii) verificabilidad del sistema, que incluye el acceso al registro de su funcionamiento, la publicidad del código fuente, la certificación de autentificación del software y la existencia del procedimiento de registro oficial de eventos durante un rango determinado de tiempo (conocido como $\mathbf{l o g}$, en lengua anglosajona, o bitácora, en lengua española). Sobre la importancia del conocimiento o la revelación del $\log$ o registro, véase el valioso documento elaborado por Pasamar (2011), así como el texto accesible de Uttendorfer y Höbel (2012: 22-27).

Desde el punto de vista de Luis Panizo Alonso (2007: 11-12; además 2013: 13-15), "es necesario garantizar una serie de aspectos en el voto electrónico" (algunos de esos aspectos se citan literalmente, pero, en el mayor número de incisos, se resume su significado o se modifica la redacción para efectos de su mejor comprensión):

a) La autenticación: Deben votar sólo quienes estén debidamente habilitados por ley o por mandato judicial.

b) La unicidad del voto: Se debe permitir votar sólo una vez y evitar modificar el resultado de la votación.

c) El anonimato: Se debe relacionar cada voto con su emisor.

d) Imposibilidad de coacción: El comprobante de emisión de cada voto -que reciben los votantes- no debe contener dato alguno sobre el sentido del voto.

e) Precisión: "El sistema debe tener la capacidad de registrar los votos correctamente y con seguridad".

f) Verificación: Cada elector debe recibir un comprobante de emisión de su voto "que le garantice que su voto será incluido en el escrutinio final".

ambiente, y los principios que gobiernan su diseño y evolución” (Diccionario Informático, http://www.alegsa.com.ar/Dic/arquitectura\%20de\%20sistemas.php). Por tanto, la arquitectura de sistemas permite "que un sistema operativo sea una interfaz útil y cómoda entre el usuario y el hardware", por tanto, a través de una serie de "rutinas" que conforman el núcleo del sistema operativo (software) un sistema estructurado de manera sólida permite leer y escribir archivos, asignar y gestionar memoria, tomar decisiones de acceso, etc. Al respecto, http://uw713doc.sco.com/en/Navpages/index.html desde http://uw713doc.sco.com/es/Navpages/sitemap.html (en mapa del sitio) a http://uw713doc.sco.com/es/SEC_admin/CTOC-IntroScur.html $\quad$ y http://uw713doc.sco.com/es/SEC_admin/_System_Architecture_SA_Definiti.html 
g) Imparcialidad: Todos los votos deben mantenerse en secreto (almacenados de alguna forma) en todo momento, hasta finalizar la votación, para evitar inducir a los sucesivos votantes.

h) Auditabilidad: Deben existir procedimientos para verificar "que todos y cada uno de los votos se hayan tenido en cuenta en el escrutinio".

i) Confiabilidad: Los sistemas deben operar de modo seguro, sin que se produzca pérdida de votos.

j) Flexibilidad: Los equipos o las máquinas utilizadas deben ser flexibles con las características de los votantes (por ejemplo, con los idiomas autorizados o con las capacidades físicas) y "compatibles con todo tipo de plataformas y tecnologías".

k) Accesibilidad: Los sistemas de votación deben permitir ser usados también por ciudadanos con discapacidad o adversidad física funcional.

1) Usabilidad: El uso de los equipos debe ser fácil y sencillo, independientemente de que el ciudadano reciba previamente un mínimo de formación o entrenamiento.

m) Eficiencia: Los equipos utilizados deben estar suficientemente disponibles en el mercado o con el proveedor respectivo y ser reutilizables.

n) Certificables: Las características y el funcionamiento de los equipos deben certificados por la autoridad competente.

o) Invulnerable: El acceso al sistema operativo empleado debe ser bloqueado por usuarios no autorizados, para evitar su manipulación y la posibilidad de fraude.

p) Compatible con la tradición electoral: El diseño del hardware y del software debe ofrecer un conjunto de medios e instrumentos lo más cercano posible a aquellos de tipo tradicional.

q) Abierto: El sistema en su conjunto (software y hardware) debe estar en condiciones de verificación en todo momento por parte de autoridades y ciudadanos.

r) Barato: El equipo adquirido debe ser competitivo en términos de costos de sistemas tradicionales.

De manera similar, el argentino Damián Obremski (2006: 13-15) afirma que los sistemas de voto electrónico deben garantizar otros requisitos y principios:

i) "Elegibilidad y autenticidad" (sólo pueden votar los electores habilitados legalmente);

ii) "Integridad" (debe comprobarse por medios idóneos la identidad de los electores);

iii) "Autenticidad" (los electores debidamente habilitados pueden votar sólo una vez);

iv) "Certificación a auditoria" (los sistemas deben ser probados por personal capacitado a efecto de certificar su funcionamiento aceptable y de auditarlos en cualquier momento);

v) “Confiabilidad” (los sistemas de voto electrónico deben funcionar sin pérdida de datos o información);

vi) "Facilidad de uso" (los medios e instrumentos de votación, cual sea su diseño, deben ser fácilmente utilizables para evitar confusiones en el elector y la autoridad); y

vii) "Exactitud y posibilidad de verificación" (los sistemas deben almacenar correctamente los votos y la información que registren a efecto de su verificación).

Por su parte, Guillermo Feierherd et al (2004: 9) proponen una serie de requisitos o principios que debe cumplir un sistema de votación, en el entendido fundamental de que "el sistema electoral en su conjunto (y el de votación en particular) debe cuantificar con exactitud (sin sesgos, sin modificaciones) las voluntades de los electores reflejadas en sus intenciones de voto". Me permito citar sólo tres de esos requisitos y omitir el relativo a la obligatoriedad del voto, además de que procuro una redacción clara en el resumen del significado de los requisitos propuestos (que pueden ser clasificados como básicos para todo tipo de sistema electoral democrático):

a) El sistema debe admitir sólo a los ciudadanos debidamente habilitados "y solamente ellos". Según Feierherd et al, esto puede considerarse bajo el principio de "universalidad". 
b) Los ciudadanos pueden votar sólo una vez y cada voto tendrá el mismo valor conforme al principio "un ciudadano, un voto". Según Feierherd et al, esto puede considerarse bajo el principio de "igualdad".

c) La identidad de los votantes no debe ser vinculada con el sentido de su voto y, por tanto, debe "garantizarse que no existe ninguna posibilidad, ni siquiera para el mismo elector, de demostrar que votó de determinada manera". Esto se ajusta satisfactoriamente al principio de secrecía, y así lo presentan Feierherd et al.

En complemento de lo anterior, Feierherd et al (2004: 9 a 10) señalan otros requisitos asociados más específicamente a los sistemas de votación electrónica, a saber (David Miguel Cortés Polo et al, 2013, proponen requisitos similares, pero agregan los de "autentificación", "unicidad", "flexibilidad", "comodidad", "ergonomía", "integridad" y "confidencialidad"):

i) Flexibilidad: "El sistema debe ser capaz de adaptarse a distintos tipos de elecciones". Pero, según los autores citados, esto puede presentar ventajas y desventajas con relación al diseño del software y la necesidad de practicar auditoría de su funcionamiento en sucesivos procesos electorales. No obstante, mi opinión es que esto mismo ocurre con los sistemas convencionales de votación, por lo que no debería derivarse de esto una consideración restrictiva para avanzar -en su caso- hacia un sistema electrónico, porque tal vez se trate de desventajas de costos relativos a un pequeño sector del equipamiento, concretamente del software.

ii) Auditabilidad: En primer lugar, esto ofrece la posibilidad de auditar todos los niveles de software y los resultados finales. En segundo lugar, esto implica la necesidad de que el sistema genere un comprobante de emisión del voto, que se imprima para entregar al elector, que éste lo deposité en una urna (en sustitución de la tradicional boleta electoral) o sea volcado automáticamente por la misma máquina utilizada en la emisión respectiva y que, luego, sirva para la verificación del resultado de la votación (por opciones votadas y en su totalidad).

iii) Conveniencia: "El sistema debe facilitar su uso aun a aquellos que no están habituados al empleo de herramientas computacionales" y el diseño de las interfaces o mascarillas o papeletas que contengan las opciones a votar debe evitar la inducción de los votantes.

iv) Disponibilidad: El sistema debe operar y prestar los servicios en el lugar y el tiempo programados. Así, la autoridad debe tomar todas las provisiones y previsiones a efecto de anular los riesgos de inoperatividad del sistema. "Si bien en razón de la distribución del sistema la caída de uno de los elementos afecta a un número reducido de electores, el simple hecho de que alguien no pueda votar, o que su voto sea perdido por una falla del sistema, atenta contra derechos constitucionalmente establecidos".

v) Fiabilidad: "El sistema debe ser fiable. La cuantificación que el sistema hace de la voluntad popular debe ser un reflejo fiel de la misma. Dicho en otros términos, todos los votos emitidos válidamente deben ser correctamente contabilizados [...]. El margen de error debe ser cero".

vi) Seguridad: El sistema debe ser diseñado para operar sin causar daño ambiental o a las personas y, por otra parte, para evitar que sea dañada la función electoral (por pérdida de datos o imposibilidad para votar durante la jornada electoral).

vii) Protección: El sistema debe estar protegido contra posibles intrusiones y alteración de datos.

Luego de las experiencias con sistemas basados en DRE, que dejaron una oscura huella en el trazado de la ruta que estaba siguiendo la revolución del voto electrónico, y en la revisión de diversos estudios sobre requisitos del voto electrónico, una serie de recomendaciones presentadas por Alejandro Prince (2005: 53 a 54) parecen rescatar fundamentalmente tanto el planteamiento crítico original de Rebecca T. Mercuri (total desconfianza en el sistema DRE) como la preocupación lejana (en 1892) de Jacobo H. Myers consistente en presentar a la máquina de votar como respuesta contra el fraude, dado que su sistema tuvo la capacidad de hacer del ejercicio de votar una operación simple, al mismo tiempo que en la conservación de la papeleta de voto garantizó la secrecía del voto. Veamos:

Para nosotros, adquiere especial importancia, al menos en los primeros momentos, las siguientes recomendaciones de carácter antropológico:

- Contemplar la utilización del denominado "Sistema Mercuri” de control.

- Asegurarse que las e-urnas no tengan conexiones online durante el comicio [sic]. Estas sólo deben establecerse para la consolidación de resultados.

- Por ahora, [...] el acto eleccionario - al menos en la Argentina- deber seguir siendo presencial. 
- Es también importantísimo que sean reproducidas las situaciones rituales del denominado "cuarto oscuro", que incluyen la privacidad.

- La propiedad del código informático a utilizar debe ser aclarada a fondo, de manera [...] que el propietario sea el Estado, y no se generen problemas en cuanto al uso futuro en otras elecciones.

Valoración preliminar de los estándares y principios

Una valoración preliminar de esa serie de estándares y principios permite reiterar que el uso de medios electrónicos de votación exige un nuevo tipo de legislación electoral para adecuar o actualizar las operaciones de organización y realización de las elecciones, así como garantizar el ejercicio de derechos fundamentales (no sólo los derechos de voto activo y voto pasivo). Sin embargo, lo más importante es que el uso de ese tipo de medios se sujete a los principios que rigen las elecciones populares y democráticas, lo cual tiene alcance en el campo de garantía de los derechos políticoelectorales.

En sintonía con ello, conviene no perder de vista la esencia de las recomendaciones presentadas por el Comité de Ministros del Consejo de Europa a los Estados de la Unión Europea, en 2004, "sobre los estándares legales, procedimentales y técnicos de los sistemas de votación electrónica", si acaso éstos se están aplicando o se prevé su aplicación, las cuales pueden ser expresadas de la siguiente manera:

- Considerar la revisión y el examen de las políticas y normativas internas a cada Estado miembro en materia de voto electrónico;

- Considerar la interrelación entre los aspectos jurídicos, procedimentales, de gestión y técnicos del voto electrónico; $y$

- Respetar todos los principios predicables de las elecciones y referéndums democráticos, a fin de dar seguridad e inspirar la misma confianza que los sistemas de votación tradicionales en todos los aspectos propios de una elección democrática.

Tratándose de recomendaciones, sin embargo, el documento revela que éstas "no obligan a los Estados miembros a modificar su respectiva normativa de procesos electorales", "siempre y cuando la citada normativa de procesos electorales respete todos los principios fundamentales de las elecciones y referéndum democráticos" (punto 2.5 de la Recomendación central). Esta precisión, y el énfasis que conlleva, permite actualizar la esencia de mi hipótesis: toda elección popular y democrática que se realice por medios tradicionales o bien se sirva de tecnologías de última generación, debe sujetarse a principios fundamentales del Estado constitucional y democrático, por lo cual el legislador siempre deberá procurar un tipo de normas aplicables que se atengan a esos principios y protejan efectivamente el ejercicio de derechos, estén o no escritos en los ordenamiento jurídicos (sobre el significado de este concepto, véase Guastini, 2004: 247-282).

En consecuencia, en la medida en que las innovaciones tecnológicas impactan no sólo la forma de llevar a cabo las elecciones, sino particularmente su esencia -consistente en la emisión del voto en completa secrecía y en un sentido libremente determinado por el votante, además de la confirmación de su sentido y su consecuente registro como válido o nulo- con mayor razón una modificación de la legislación electoral debe cuidar la subsistencia de los principios aplicables de derecho electoral y la incorporación de otros que hagan confiable y transparente todo el proceso de renovación de la representación política y de los órganos de poder público, desde el momento en que inicia dicho proceso y hasta que se valida su realización y sus resultados, pasando por cada uno de los actos propios de la jornada electoral.

Estas consideraciones complementarias permiten confirmar que los sistemas de votación electrónica deben ser incorporados en los procesos electorales democráticos como medios para facilitar técnicamente la emisión-recepciónescrutinio-cómputo-registro de votos, independientemente del costo económico que en principio ello puede implicar; sin embargo, con base en algunas experiencias relevantes que emplean la modalidad presencial de este tipo de sistemas de votación, dichos procesos se mantienen sujetos a principios jurídicos que garantizan que cada voto contará en el mismo sentido de su emisión. Por lo tanto, la regulación jurídica aplicable a ese tipo de experiencias está estructurada por estándares coherentes con el carácter democrático de las elecciones populares.

Se pueden observar tres segmentos de esta precisión:

a) La constatación de dos hechos: un creciente interés por adoptar algún sistema de votación electrónica y la promoción continúa de desarrollos tecnológicos informáticos de transferencia de datos en tiempo real;

b) la preocupación común acerca de la sujeción de las votaciones electrónicas a principios jurídicos democráticos; y 
c) la necesidad de identificar la especificidad de una regulación jurídica aplicable a votaciones electrónicas que sea coherente con la garantía efectiva de derechos político-electorales.

Por consecuencia, también conviene formular algunas premisas que pueden facilitar la conexión entre lo que se pretende subrayar (el problema de la ausencia de regulaciones suficientemente sustentadas en principios idóneos) y los requerimientos normativos básicos de cualquier elección popular de naturaleza democrática.

En efecto, hay una tendencia creciente a nivel mundial -particularmente desde la década de 1990-a incorporar nuevas tecnologías aplicables a las elecciones, al mismo tiempo que es visible la no correspondencia entre normas jurídicas tradicionales y el uso de tecnologías de "última generación" que impactan la concepción de las elecciones en lo relativo al procedimiento de emisión-recepción-escrutinio-cómputo-registro de votos.

Si la emisión del voto debe mantener su efectividad y realizarse con plena secrecía y libertad, el uso de medios de votación electrónica debe entonces sujetarse en todo momento a reglas y principios jurídicos que hagan efectiva la voluntad popular y satisfagan los fines del Estado democrático y constitucional. La premisa de todo ello es que los ciudadanos generalmente concurren a una votación con una noción general del procedimiento que deben seguir a tal efecto, con la convicción de que cuentan de inicio con un instrumento que acredita su derecho a participar del procedimiento: la credencial para votar o cualquier acreditación supletoria autorizada por la ley o las autoridades competentes; pero, además, tienen la idea de que podrán votar conforme a un procedimiento común o igual para todos, independientemente de las modificaciones de los medios utilizados para personas con capacidades diferentes (o con "diversidad funcional"). Por tanto, una regulación apropiada para el uso de sistemas de votación electrónica debe procurar la conservación del acto electoral y las condiciones comunes del procedimiento de votación.

Indudablemente, el ciudadano no es un actor adicional -simplemente accesorio- al procedimiento de votación, sino que constituye la parte actora fundamental, la parte creadora de una decisión trascendental. El hecho es que los ciudadanos conocen de alguna manera el procedimiento de votación, y cualquier modificación en esta esfera requiere considerar la importancia de la educación cívica, la cultura cívica o la cultura política orientada por valores y principios democráticos y por hábitos comunes.

En esta misma línea de características, requisitos y recomendaciones relativas al voto electrónico, debo mencionar también la serie de "características" compiladas por Domínguez Campos en una revisión de estudios, citada por Julio Téllez Valdés (2010: 19-23). Puesto que arriba se han comentada varias características similares, referidas por algunos autores también consultados por Domínguez Campos, conviene señalarlas sólo por su denominación o por su objetivo. Así, el voto electrónico debe ser "auténtico", accesible, "anónimo", "certificable o auditable", "comprobable", confiable, "comprensible para el votante" y fácil de usar, además de que "el sistema debe ser robusto" y "compatible con mecanismos de votación convencionales", tener "código abierto" y capacidad de "veracidad", propiciar la reducción del costo de las elecciones, hacer imposible la revelación del sentido del voto para garantizar la imparcialidad y neutralidad de la autoridad, permitir que los ciudadanos puedan votar desde cualquier parte del mundo con claves propias de seguridad, admitir la capacidad de verificación del voto por cada votante, asegurar que el ciudadano vote sólo una vez y no se modifique el resultado total al cierre de la votación, y demostrar que la emisión del voto es "ágil, sencilla y rápida".

Por otra parte, Rodrigo Antonio Porras Robles (2012: 2) es uno de los autores que habla positivamente de los sistemas de votación electrónica, aunque admite que pueden ser mejorados para cumplir con exigencias técnicas y jurídicas. Al respecto, dice que

La votación electrónica tiene potencialmente múltiples ventajas en comparación con otros sistemas de votación. Puede reducir drásticamente el tiempo del recuento de votos, así como el número de errores en dicho proceso debidas a fallas humanas o por anotación deficiente de las papeletas. También permite a los votantes emitir su voto en cualquier recinto habilitado sin restricciones geográficas, disminuir la posibilidad de fraudes por autoridades maliciosas o comprometidas (por medio de administración distribuida de la elección, en particular, del recuento de votos), y obtener verificación universal de la elección. Esta última característica permite garantizar un proceso completamente transparente ante cualquier observador interno o externo, quien puede verificar -en forma online - la realización correcta de cada una de las etapas del proceso de votación.

No sobra agregar aquí un requisito poco mencionado en los primeros estudios sobre voto electrónico, pero que ha sido destacado con el desarrollo de nuevas tecnologías de identidad personal. Se trata del procedimiento de identidad mediante el uso de una técnica biométrica. Esta técnica fue aplicada por la empresa SmartMatic en las elecciones presidenciales de Venezuela, en 2012 (ganadas por Hugo Chávez) y 2013 (ganadas por Nicolás Maduro). Pero, según 
Fanny Kertzman (2013), "la gran crítica que se le ha hecho al sistema electoral venezolano es que la misma máquina de votar tiene un módulo que capta la huella del votante, de manera que es posible saber el voto del ciudadano y se acaba el voto secreto [...]", lo cual puede ser utilizado con fines de control político, clientelar o coercitivo.

Finalmente, una recomendación que debe ser tomada en cuenta por la autoridad organizadora de las elecciones tiene que ver con la homologación del conjunto del sistema y, por tanto, de los equipos programados para su uso el día de la jornada electoral. No obstante que por limitaciones financieras para renovar los equipos en cada proceso electoral puede ser difícil actualizar el hardware a emplear, es recomendable que éste tenga las mismas características en el 100 por ciento de las casillas (mesas receptoras o centros de votación), con la finalidad de evitar suspicacias y la desconfianza entre los votantes, y aun la impugnación de los resultados de casilla. Aunque en ciertos casos puede haber autorización legal o acuerdo de la autoridad organizadora de las elecciones para proveer elementos diferenciados en un número determinado de casillas o centros de votación, es imprescindible que los ciudadanos, los candidatos, los partidos políticos y sus representantes lo sepan ex profeso y con anticipación debida, independientemente de la obligación de la autoridad responsable de dar transparencia a los actos respectivos con oportunidad y claridad.

Después de todo, como sostiene Fernando Tuesta Soldevilla (2004: 57-58), a propósito de una serie de cambios provocados por la introducción del voto electrónico, se advierte un cambio en muchas vías y niveles que afectan no sólo el procedimiento técnico de la votación, sino la propia conducta electoral y aun los sentimientos de los ciudadanos a la hora de ejercer uno de sus derechos fundamentales y humanos, ese del que Aristóteles ya tomaba como la base de la politicidad del hombre, de su existencia en comunidad política: el derecho de decidir de alguna manera, en algún sitio y de un modo específico sobre asuntos públicos. Y al respecto me permito citar extensamente las palabras de Tuesta Soldevilla, porque, algo que tal vez ya habíamos percibido, ahora lo podemos entender de manera impresionante:

El voto electrónico produce un impacto significativo sobre los materiales, actividades y procedimientos electorales: eliminación de las boletas de votación, eliminación del padrón de electores impreso, eliminación del acta electoral (y sus copias), eliminación de la urna o ánfora electoral, reducción del número de mesas y de locales de votación, reducción del número de miembros de mesa, eliminación de los votos por error, eliminación del llamado error material, disminución del tiempo de entrega de resultados, eliminación del resultado provisional, disminución del personal eventual contratado para un proceso electoral, y ahorro en el presupuesto público en el mediano plazo.

Asimismo, el voto electrónico supone un cambio profundo en los hábitos de los ciudadanos. En principio, desaparece el concepto de «mesa de sufragio» que es reemplazado por un ambiente que incluso físicamente es distinto: el «módulo de votación» (que agrupa a varias mesas de votación manual, pero multiplicando el número de votantes por cada cabina de votación). Al ingresar al aula o ambiente de votación, el elector ya no encontrará las acostumbradas mesas con ánfora, tinta indeleble, tampón, actas padrón con la lista de votantes y una amplia variedad de otros formularios en papel. En su lugar encontrará una computadora con teclado, ratón (mouse) o pantallas sensibles al tacto (touch screen). Y, en lugar de los miembros de mesa, encontrará operadores frente a una computadora que «identificará» al elector.

El padrón electoral es reemplazado por el casi imperceptible «escaneo» del código de barras del documento de identidad mediante una pistola lectora. El elector ya no firmará, ni estampará su huella digital, ni marcará su dedo con tinta indeleble. La cédula de sufragio y el ánfora son reemplazadas por una pantalla sensible, un ratón o el teclado de una computadora. Ya no habrá necesidad de marcar opciones en un papel ni siquiera de llenar una gran cantidad de actas.

IDEA Internacional (2011: 7), por su parte, ha subrayado la importancia de la emisión de comprobantes impresos para los votantes como forma de verificación ex post de los resultados por mesa de votación, sin dato alguno de revelación del sentido del voto individual, y como condición básica para que los votantes mantengan su confianza en el sistema de votación electrónica (subrayo con negritas en el texto citado):

Debido al requerimiento de proteger el carácter secreto del voto, deben evitar establecer cualquier tipo de conexión entre la identidad del votante y el voto emitido. Esto en sí mismo supone un desafío, ya que lo normal es que las TIC estén inherentemente construidas para rastrear y monitorear las transacciones que se efectúan con ellas. Aún más importante, romper el vínculo entre el votante y el voto implica que al examinar un sistema de voto electrónico después de una elección no puede probarse directamente que todo voto fue contabilizado de la misma forma en que fue emitido. De ahí la excepcional importancia de contar con pruebas indirectas de la validez de los resultados electrónicos, por ejemplo, mediante el uso de comprobantes impresos de los votos o mediante un sistema de verificación, combinados con rigurosos procedimientos de seguridad y control de calidad. Sin estos mecanismos, las 
manipulaciones o los errores en los resultados generados por el e-voto podrían pasar inadvertidos durante mucho tiempo.

Con un sistema electrónico de votación, según IDEA Internacional (2011: 9), se observan algunos problemas ("debilidades"); pero, con relación a la necesidad de llevar a cabo el escrutinio de los votos emitidos, me permito citar puntualmente algunos de ellos:

- "Posibilidades limitadas de recuento de votos".

- "Posibilidad de conflicto con el marco legal vigente".

- "Es posible que la ciudadanía desconfíe de las elecciones con voto electrónico como resultado de las debilidades antes mencionadas".

El único instrumento para llevar a cabo una especie de compulsa de la votación emitida se constituye con el conjunto de los comprobantes de los votos emitidos, generados individualmente, y, en última instancia, con el llamado log o registro del propio sistema electrónico, el cual puede constituir una prueba pericial de gran valor judicial. Si estos dos modos - diferentes- de probar simétricamente tanto la cantidad como el sentido de la voluntad general, sin posibilidad alguna de vincular nombres de los votantes, se conservan juntos, entonces ello sería la base para propiciar la confianza en el subsistema de votación electrónica, en un momento determinado y como un efecto en el largo plazo.

La sentencia BvC 3/07-2 BvC 4/07 del Tribunal Constitucional Federal (Bundesverfassungsgericht) de Alemania y sus efectos doctrinales

Esta sentencia, pronunciada el 3 de marzo de 2009 en el proceso de Queja de Control Electoral contra la resolución del Bundestag (Senado) alemán del 14 de diciembre de 2006 (WP108/05 - BTDrucks 16/3600), relativa a la inconstitucionalidad de la prescripción sobre el empleo de medios electrónicos para las elecciones al $16^{\circ}$ Bundestag y al Parlamento Europeo, es relevante para entender las exigencias normativas a los sistemas de votación electrónica. Básicamente, en ella se señala la ausencia de controles acordes con el principio de publicidad de la elección. La omisión de dichos controles por parte del legislador constituye la posibilidad de que -al ocurrir errores en cualquiera de los momentos del proceso de votación- no sólo se viole el principio de secrecía del voto, debido a manipulaciones intencionales de los medios utilizados, sino que además se pierda en la oscuridad el curso que sigue el acto de votación, porque tal vez dicho acto no concluya en la emisión efectiva del voto.

Sobre el principio de publicidad, en el numeral 35 de la sección de "Fundamentos" de esa sentencia se argumenta que "debe garantizar una realización ordenada de la elección y garantizar la correcta integración del parlamento". Sin embargo, "el control debe hacer hincapié en el secreto del voto y que además el voto no se pueda modificar, que el resultado sólo debe contabilizar los votos emitidos". En virtud de ello, y por la ausencia de los controles aludidos, el uso de medios electrónicos de votación "impide un control efectivo por parte del público" y la autoridad electoral, "ya que la determinación del resultado se realiza en el interior del aparato [electrónico] electoral". En el numeral 36 de esa misma sección se sugiere un tipo de control que supone que todo proceso -y, para el caso, de tipo electoral- que resulta de una concatenación de operaciones humanas y artificiales, implica la generación de pruebas fehacientes de las operaciones ejecutadas efectivamente: "La publicidad de una elección con aparatos electorales sólo puede garantizarse con mecanismos de control como por ejemplo la impresión de un protocolo en papel del voto emitido". Pero eso sólo tratándose operaciones realmente ejecutadas en el proceso de votación, porque aún hay que tomar en cuenta los mecanismos de control que deben diseñarse y aplicarse en relación con el hardware y el software utilizados para la ejecución misma, los cuales, como bien se dice en el correspondiente numeral 37, "no son controlables por el público", por lo que ahora queda en claro que se trata de dos niveles de verificación exigibles en un proceso de votación popular que utiliza medios electrónicos (incluso si no fueran electrónicos): en primer lugar, el nivel del diseño y uso de medios materiales para la emisión-recepción-cómputo de los votos; en segundo lugar, el nivel que concierne a la ejecución de operaciones en el acto tríadico electoral. Ambos niveles son fundamentales para la realización del llamado "sufragio efectivo".

La sentencia invocada, emitida por el Tribunal Constitucional Federal Alemán, resume de la siguiente manera el axioma de aplicación del principio de publicidad y de mecanismos de control público sobre elecciones populares que utilizan medios electrónicos:

1. El principio de la publicidad de la elección del artículo 38 en relación con el artículo 20 párrafos 1 y 2 ordena que todos los pasos esenciales de la elección están sujetos al control público, en la medida en que otros intereses constitucionales no justifiquen una excepción. 
2. En la utilización de computadoras electorales o urnas electrónicas, el ciudadano debe poder controlar los pasos esenciales del acto electoral y la determinación del resultado de manera fiable y sin conocimientos técnicos especiales.

Relacionado con lo anterior, Javier Guillem Carrau (2010: 158) dice de manera brillante que "la ausencia de visualización y comprensión del proceso electoral basado en el voto electrónico por la ciudadanía no se compensa por cautelas técnicas suplementarias de certificación y auditoría previa. La cuestión no es que el proceso sea controlable sino comprensible para los actores electorales, no constituyendo argumentos de peso suficientes ni la disminución de los errores involuntarios del elector, ni la rapidez en la publicación de los resultados". Además, al citar a Jordi Barrat i Esteve, sostiene que la confianza de los electores en el voto electrónico no se ha producido porque éste "no permite alcanzar una comprensión universal del sistema que, debido a su complejidad técnica, sólo será entendido por un núcleo reducido de especialistas". En concordancia con estos principios, es exigible que a los ciudadanos se les otorgue el derecho de participar en las funciones de certificación y auditoría, previamente al inicio de la jornada electoral y durante ella, a fin de dar cumplimiento concreto al principio de máxima publicidad.

Para reforzar lo anterior, Josep $\mathrm{M}^{\mathrm{a}}$ Reniu Vilamala (2008: 41-42) señala una serie de dificultades que puede enfrentar la pretensión de verificación que requiere el voto electrónico para ser compatible con las exigencias de elecciones democráticas, si bien en la modalidad de voto electrónico remoto se vuelve prácticamente imposible tal compatibilidad. Al respecto, sostiene que

[...] en un sistema con "urnas electrónicas en entornos controlados, todo parece indicar que la única medida posible para generar confianza de manera equiparable es la introducción de los recibos de papel verificados por el votante (VVPT). Aunque ello no es suficiente, habida cuenta de la necesidad de confirmar la correcta transmisión de los datos almacenados por las urnas incluso habiéndose certificado la congruencia de los datos almacenados respecto de los recibos de votación depositados en la urna. Y no lo es por dos razones: en primer lugar, porque, como ya se ha señalado anteriormente, los recibos de votación deben tener un carácter meramente temporal durante el período inicial de introducción de las urnas electrónicas; en segundo lugar, porque dicho proceso de verificación debería venir acompañado por la posibilidad de realizar auditorías de cada una de las urnas electrónicas, por parte de personal competente técnicamente".

Por lo anterior, y a efecto de concretar el principio de máxima publicidad y propiciar la confianza en el sistema empleado, desde el punto de vista del votante, Reniu Vilamala sugiere:

a) “[...] contemplar la realización de procesos de congruencia entre los datos computados por las urnas electrónicas y los recibos de votación depositados por los electores en las urnas tradicionales. Este sistema no puede aplicarse, obviamente, a todo el conjunto de urnas electrónicas, sino que debe basarse en un proceso de «catas», con una selección aleatoria de las urnas a auditar que sea además representativo del total de colegios electorales y urnas electrónicas. No obstante lo recomendable de esta medida, debe tenerse presente que su carácter es limitado en el tiempo, por lo que en un plazo relativamente breve (entre tres y cinco procesos electorales) debería reconsiderarse".

b) Establecer "protocolos claros y transparentes para la realización de auditorías técnicas de la solución de voto electrónico que se vaya a emplear", y, en especial, debe "permitirse el acceso al código fuente y a la inspección de todo el proceso de fabricación de las urnas electrónicas o de preparación de la plataforma remota de votación, así como también exigirse a dichos colectivos el seguimiento de un protocolo de auditoría previamente establecido".

c) Finalmente, debe consolidarse normativamente la certificación de los equipos empleados, del sistema operativo y de las aplicaciones de usuario, y establecer en la ley, por tanto, "qué agencias -públicas o privadas- deben tomar parte en dichos procesos, qué aspectos deben ser objeto de certificación, qué duración temporal debe tener dicha certificación o, finalmente, qué difusión deben darse a los resultados obtenidos".

Ahora bien, en el contexto de fuerte -pero también cuestionada- promoción del voto electrónico en la Provincia de Salta, situada en el noroeste de Argentina, el Senador provincial argentino Alberto Conde hizo énfasis público, el 27 de febrero de 2003, en el código de fuente (conjunto de instrucciones escritas en lenguaje de programación que deberá realizar la computadora) ${ }^{34}$ para que sea puesto bajo la mirada pública y debido control, como condición esencial

${ }^{34}$ Sobre el concepto de código fuente en el contexto del debate sobre software libre y software propietario, véase el
excelente trabajo de Montserrat Culebro Juárez, Wendy Guadalupe Gómez Herrera y Susana Torres Sánchez (2006).
Estas autoras inician su trabajo con una definición precisa de software, incluso diferenciado de "código fuente" en sus
distintas modalidades: "Probablemente la definición más formal de software es la atribuida a la IEEE (Instituto de
Ingenieros Eléctricos y Electrónicos), en su estándar 729: la suma total de los programas de cómputo, procedimientos, 
para impedir la alteración de los votos: "Para que sea una alternativa segura y realmente efectiva, el voto electrónico debe cumplir con una garantía fundamental: impedir la alteración de los resultados. Si el software utilizado por la urna electrónica no es diseñado, probado y publicado en modo de código fuente, al igual que el usado para el recuento de votos, la seguridad no está garantizada" (Conde, 2003: 2). Además, el Senador provincial mencionado subrayó la necesidad de adecuar el Orden Jurídico Nacional por cuanto a la tipificación de los delitos electorales informáticos. Por la importancia que tiene el informe presentado por el Senador Alberto Conde, especialmente por las propuestas específicas ahí contenidas, me permito citar in extenso ésta última, con un subrayado de mi parte con negritas y cursivas (Conde, 2003: 34-35):

Nuestra propuesta se basa en recorrer un camino inverso al planteado, instalando primero el marco jurídico apropiado para que luego se consense el instrumento que usará la sociedad para legitimar a sus representantes.

Pero esta propuesta estaría incompleta si no le agregamos la técnica necesaria para producir la migración hacia el nuevo sistema. A esto proponemos que se implemente una solución mixta temporal dentro de lo que permite el actual marco jurídico. Una técnica que permita la comprobación de la seguridad y fiabilidad del sistema que finalmente se usará.

El principal requisito de esta técnica de prueba es que las UE [urnas electrónicas] cumplan con las condiciones tecnológicas que hemos detallado y que estén dotadas de una impresora de matriz de puntos y no térmicas (debido a su baja confiabilidad y corta duración del comprobante).

Se podría proceder a una modificación del sistema usado actualmente para que permita al votante usar la UE. Esta imprimiría una boleta con el resultado de la selección del elector, que sería colocada en un sobre tradicional.

De esta forma, el votante podría chequear si emitió el voto correctamente y luego depositar "con confianza" el sobre.

Esta boleta se usaría para el recuento del cierre y sería la única que tiene validez. Pero también sería la comprobación del sistema electrónico hasta que se obtenga la confiabilidad suficiente en este.

Una vez lograda esta confiabilidad se podría suplantar un sistema por el otro cumpliendo con los demás requisitos expresados.

Con respecto a la publicidad del código fuente, hay que recordar que Estonia ya opera su sistema de votación electrónica con código fuente abierto. El debate en el mundo se ha centrado en parte sobre la necesidad de publicitar dicho código, a fin de revelar en última instancia, al llevarse a cabo alguna auditoría del sistema empleado, si fue alterado o vulnerado, o no, y se ha llegado a plantear si no con tal publicitación se estaría en realidad en la modalidad de código fuente libre, sin derechos que pueda reclamar alguien como su propietario.

En la Provincia de Salta, Argentina, aún se discutía en 2012 la imperiosa necesidad de publicitar el código fuente y certificar las máquinas de voto electrónico, a fin de transparentar el procedimiento electoral y dar confianza a todos los actores políticos, además de los votantes, pero las reglas sólo autorizan que los partidos dispongan del código fuente, lo cual ya es un avance para romper la opacidad reinante hasta ahora (véase al respecto el dato en línea: "III Debate Público: Voto electrónico en Salta", 22 de agosto de 2012, http://www.fmcapitalsalta.com/noticias/1446/iiidebate-publico-voto-electronico-en-salta.html). En efecto, de acuerdo con el marco normativo de la Provincia de Salta, Argentina, el Tribunal Electoral de esta Provincia debe garantizar, entre otras cosas (subrayo la referencia al código fuente) (OPE-ACEP, 2013: 9):

- "Que exista siempre el respaldo en papel de cada voto emitido por los electores".

- "Que las fuerzas políticas intervinientes puedan controlar y fiscalizar la elección en sus diversas etapas incluyendo la posibilidad real y concreta de conocer y auditar cómo funciona el sistema de voto con boleta electrónica y su código fuente".

- "Que las fuerzas políticas intervinientes, a través de sus fiscales puedan efectuar el control efectivo, visual y de conteo del escrutinio provisorio".

- $\quad$ "Que el sistema de boleta electrónica y su registro impida la posibilidad de conocer el sentido del sufragio manteniendo con absoluta certeza el derecho al voto secreto".

reglas, documentación y datos asociados que forman parte de las operaciones de un sistema de cómputo. Bajo esta definición el concepto de software va más allá de los programas de cómputo en sus distintas formas: código fuente, binario o código ejecutable, además de su documentación. Es decir, el software es todo lo intangible. Software es también conocido como programática o equipamiento lógico, esto es el conjunto de programas que puede ejecutar el hardware para la realización de las tareas de computación a las que se destina. Se trata del conjunto de instrucciones que permite la utilización del ordenador o computador (PC, Personal Computer). El software es la parte intangible de la computadora, es decir, programas, aplicaciones, etc.". En nota anterior se ha proporcionado una definición similar de software, sin considerar al "código fuente". 
- "Que el lugar previsto para la votación y donde se coloquen las máquinas de boleta electrónica aseguren el derecho de los ciudadanos al voto secreto".

- "Que las máquinas estén dispuestas de modo que las autoridades de mesa tengan visualización sobre las mismas a los fines de garantizar el cumplimiento de las prescripciones de la presente Ley".

Luis Panizo Alonso (2013: 45) señala al respecto que, con la finalidad de garantizar la seguridad de los sistemas, la debida operación de los procedimientos asociados, el cumplimiento de los estándares establecidos y la eficaz certificación de los sistemas, es necesario:

a) "valorar el uso del software con código abierto como único plenamente transparente";

b) "separar físicamente el interfaz del votante, de la votación en sí y del proceso de escrutinio"; y

c) "desarrollar los protocolos de seguridad para permitir al votante, antes y después del escrutinio, verificar que su voto no ha sido manipulado u omitido".

Desde mi punto de vista, se trata de tres condiciones fundamentales para dar respuesta satisfactoria a las exigencias cardinales de:

- Fiabilidad del sistema de voto electrónico;

- $\quad$ Respeto al principio de secrecía del voto; y

- Ejercicio oportuno y libre del derecho del votante a controlar el curso y la autenticidad de su voto, hasta el momento de su integración en el resultado final en el mismo sentido y cantidad, sin alteración de su individualidad ni de la formación de la voluntad colectiva.

Un resumen de condiciones jurídicas similares que deben ser la base de una regulación específica del voto electrónico puede ser elaborado de acuerdo con una serie de recomendaciones formuladas por Manuel Delgado-Iribarren $G^{a}-$ Campero (2008: 2 y 20-21).

a) A pesar de las ventajas o facilidades de las tecnologías, su uso en los procesos electorales no debe ser "en detrimento de principios y valores conquistados con mucho esfuerzo por las sociedades organizadas democráticamente";

b) Dada "la intangibilidad de los medios electrónicos" y por la naturaleza "personalísima y secreta" del voto, "[...] resulta prioritario en cualquier proyecto de votación electrónica una especial vigilancia del respeto estricto de las garantías jurídicas del derecho fundamental de sufragio consagradas en todos los ordenamientos jurídicos de los Estados democráticos". En consecuencia, "no pueden implicar una reducción de los niveles de garantías conseguidos sin ellas".

Por lo tanto, en aras de "la pureza del procedimiento electoral", Delgado-Iribarren $\mathrm{G}^{\mathrm{a}}$-Campero (2008: 7-8) propone que:

i) "El procedimiento debe garantizar que los resultados reflejen con exactitud la voluntad de los electores, sin que se puedan producir manipulaciones que excluyan votos válidamente emitidos o que añadan otros indebidos".

ii) "El sistema debe estar dirigido y controlado por autoridades electorales independientes e imparciales", y debe ponerse cuidado en la responsabilidad que esto implica y evitar en lo posible que esta función se traslade a terceros.

iii) Puesto que "la transparencia global del sistema resulta más difícil de concretar", es necesario dar "visibilidad" a los trámites propios del procedimiento electoral, "con la participación y el control por los protagonistas de las elecciones", particularmente por medio de "la verificación previa de la idoneidad de los equipos y programas utilizados", así como de la verificación al inicio de las votaciones, al cierre de la votación y durante el escrutinio y cómputo de los votos.

iv) Finalmente, puesto que cualquier sistema de votación -y más tratándose del voto electrónico - requiere de la confianza de los ciudadanos, cabe guardar cautela ante la sustitución del tradicional sistema de voto.

A manera de conclusión

A pesar de que en algunos países las deficiencias de diseño y operación de algunos sistemas electrónicos de votación popular técnicamente revelan zonas de vulnerabilidad de éstos, su identificación y la promoción de soluciones informáticas y administrativas efectivas contrarrestan el pesimismo que reina en algunos círculos políticos, intelectuales y gubernamentales sobre el uso de ese tipo de sistemas. Indudablemente, las tecnologías electrónicas de votación continúan apareciendo como una alternativa a los defectos de los medios tradicionales basados literalmente en papel y lápiz, sobre todo tratándose de cuerpos electorales cuantitativamente enormes y distribuidos en múltiples y complejas circunscripciones o demarcaciones electorales.

Los problemas propios de esos sistemas tradicionales subsisten en muchos países, y consisten básicamente en: 
a) La falta de certeza sobre la ruta efectiva que siguen algunas boletas electorales, una vez que el elector las recibe, sobre todo en sistemas políticos sustentados todavía en relaciones clientelares, de soborno y de presiones políticas;

b) el lapso relativamente excesivo que sigue al cierre de la votación dedicado al escrutinio, cómputo y registro oficial de resultados de casilla o de mesas de votación; y

c) la falta de resultados totales, oportunos y oficiales, concluida la jornada electoral.

Así, los principios de certeza, transparencia, seguridad jurídica, secrecía, libertad y autenticidad, se ven afectados gravemente por factores extralegales y por un sistema tradicional de votación que fragmenta los medios de emisión del voto y oculta relativamente el procedimiento de cómputo e integración de resultados. Paradójicamente, como en el caso en que se han adoptado sistemas de recuento preliminar de resultados electorales, el uso de tecnologías de última generación ha llegado a agravar la erosión de la confianza en los medios tradicionales de votación y en la misma función electoral ligada a ellos, particularmente cuando: a) se descubren errores de asentamiento de datos en las actas de escrutinio y cómputo; y b) no existe acuerdo entre los funcionarios de casilla para calificar la validez o nulidad de votos en boletas con marcas dudosas.

En definitiva, la rusticidad de los sistemas de votación tradicionales está en tela de juicio. Pero, paradójicamente, una propuesta de incorporación de tecnologías electrónicas de votación es inviable cuando, tratando de resolver sólo o prioritariamente problemas operativos y administrativos propios de la jornada electoral, omite aspectos de fondo que pueden ser clasificados en dos sectores: un primer sector, relativo a la garantía del ejercicio de derechos políticoelectorales mediante reglas y procedimientos ad hoc; y un segundo sector, relativo a los principios rectores de toda elección popular y democrática, preexistentes a dichas reglas y procedimientos y, por tanto, fundamentales a todo régimen democrático. Así, cabe reiterar que, en todo proceso electoral, independientemente de que se utilicen o no medios electrónicos de votación, la prioridad sigue siendo los derechos de los votantes, de modo que su protección y garantía deben siempre presidir las decisiones sobre el tipo de medios materiales y los modos que pueden ser idóneos para su realización o ejercicio.

Por otro lado, todas las previsiones para proveer la infraestructura necesaria, así como para responder eficaz y oportunamente a posibles situaciones de fallas, omisiones o errores de tipo técnico o administrativo, deberán estar anticipadas como una función legal de respuesta institucional, pero la especificidad y la distribución de tareas y servicios para cumplir esta función y los procedimientos correspondientes deben ser detallados tanto en las reglamentaciones como en los manuales respectivos. De ninguna manera es recomendable que la adopción e implementación de un sistema de votación electrónica quede a la discrecionalidad de la autoridad electoral, aun si así puede ser posible en una modalidad de diseño normativo, porque cuanto más amplio el umbral de discrecionalidad mayor el riesgo de vulnerabilidad del entramado jurídico e institucional. La discrecionalidad reduce directamente la certeza de los actos de autoridad, pues abre un margen de ignorancia de lo que puede decidirse, sobre todo cuando hay un ambiente de desconfianza sobre la actuación y la honestidad de la autoridad. Si la desconfianza es uno de los problemas que hay que combatir en todo proceso electoral, entonces la regulación de un sistema de votación electrónica debe evitar un tipo de disposiciones laxas o altamente flexibles y, todavía más, omisiones intencionales (producto de irresponsabilidad o de pereza legislativa).

Del mismo modo, como es recomendable para el caso de transiciones de un subsistema electoral a otro, de un subsistema con boleta impresa en papel con marcado manual a un subsistema electrónico, en la ley secundaria debe ser establecido expresamente que la implementación del sistema de votación electrónica de que se trate se efectuará de manera progresiva (por etapas, durante dos o más procesos electorales) y escalonada (primero en algunas casillas o secciones o distritos, luego en otras), pero con carácter definitivo.

Sin duda, a partir de los desafíos que presenta la circunstancia de la pandemia del COVID-19 a los procesos electivos populares, es posible concentrar los esfuerzos institucionales para mejorar y acelerar el tránsito hacia la adopción escalonada pero generalizada del voto electrónico, siempre que así sea necesario o ventajoso a los derechos de la ciudadanía.

\section{Fuentes consultadas}

Adames Suari, Guillermo Ramón (2009), "El voto electrónico: un resumen de consideraciones para su legislación en México", en Revista Legislativa de Estudios Sociales y de Opinión Pública núm. 4, volumen 2, CESOP-Cámara de Diputados, México, diciembre de 2009, pp. 315-340. Liga de acceso:

http://dialnet.unirioja.es/servlet/articulo? codigo $=3224344$ 
Aguilar Idáñez José María y Ezequiel Ander-Egg (1994), Evaluación de servicios y programas sociales, Lumen, ISBN 950-724-403-6, Argentina, 175 pp.

Aiken, Lewis R. (2003), Tests psicológicos y evaluación, Undécima Edición, Pearson Educación de México / Prentice Hall, México, 544 pp. Liga de acceso: http://biblio3.url.edu.gt/Libros/tests_p/1.pdf al http://biblio3.url.edu.gt/Libros/tests_p/17.pdf

Álvarez Conde, Enrique (1991), "Los principios del derecho electoral", en Revista del Centro de Estudios Constitucionales núm. 9, España, mayo-agosto de 1991. https://dialnet.unirioja.es/ejemplar/101839

Ballinas Valdés, Cristopher (2011), Participación política y las nuevas tecnologías de la información y la comunicación, Tribunal Electoral del Poder Judicial de la Federación, serie Temas Selectos de Derecho Electoral núm. 25, México, 55 pp. Liga de acceso: http://www.te.gob.mx/documentacion/publicaciones/Temas_selectos/25_participacion.pdf

Barrat i Esteve, Jordi (2004), “Tipología de urnas electrónicas. Su necesidad y justificación”, en ¿Hacia qué sociedad del conocimiento?, II Congreso del Observatorio de la Cibersociedad, Barcelona, ISBN: 84-609-7126-0, http://www.monografias.com/trabajos32/tipologia-urnas-electronicas-necesidad-justificacion/tipologia-urnaselectronicas-necesidad-justificacion.shtml y http://www3.unileon.es/dp/aco/area/jordi/treballs/evot/ocs.pdf

Barrat i Esteve, Jordi (2004), "El derecho de sufragio ante el reto de las votaciones electrónicas. Informe sobre las pruebas desarrolladas en Jun (Granada)", http://www3.unileon.es/dp/aco/area/jordi/treballs/evot/jun_xile.pdf

Barrat i Esteve, Jordi (2004), "Marco jurídico para la implantación de las urnas electrónicas", comunicación presentada en el Simposio Urna Electrónica para la Emisión del Voto Ciudadano, Instituto Electoral del Distrito Federal, México, 16 pp. http://www3.unileon.es/dp/aco/area/jordi/treballs/evot/iedf.pdf

Barrat i Esteve, Jordi (2007), "El voto electrónico en Latinoamérica: Radiografía de un proceso en vías de consolidación", en aa.vv. Voto electrónico. Estudio comparado en una aproximación jurídico-política (Desafíos y posibilidades), Fundap, Colección Fundap Política y Administración Pública, Querétaro, México, pp. 115-178, (ISBN: 9685434-66-9).

Barrat i Esteve y Josep Ma. Reniu (2004), Democracia electrónica y participación ciudadana. Informe sociológico y jurídico de la consulta ciudadana, Ayuntamiento de Madrid / Observatorio Voto Electrónico, Madrid, noviembre de 2004, 76 pp. http://www3.unileon.es/dp/aco/area/jordi/treballs/evot/libreesp.pdf

Barrientos del Monte, Fernando (2011), "Pertinencia técnica y oposición social al voto electrónico", en RAP. Revista de Administración Pública 126, volumen XLVI, núm. 3 de septiembre de 2011, INAP, México, pp.91-107. Liga de acceso: http://www.inap.mx/portal/images/pdf/rap126.pdf

Cardozo Brum, Myriam Irma (2006), La evaluación de políticas y programas públicos, Miguel Ángel Porrúa, México, $374 \mathrm{pp}$.

Carrau, Javier Guillem (2010), "El voto electrónico: régimen electoral general o legislación electoral autonómica", en Asamblea (Revista parlamentaria de la Asamblea de Madrid) núm. 23, Madrid, pp. 149-168. Liga de acceso: http://dialnet.unirioja.es/servlet/articulo?codigo $=3438778$

Carré de Malberg, Raymond (2001), Teoría general del Estado, FCE, segunda reimpresión, México, 1327 pp.

Castells, Manuel (1997), La era de la información. Economía, sociedad y cultura, volumen I: La sociedad red, Alianza editorial, Madrid, España. La publicación de la obra en tres volúmenes, correspondiente a la segunda edición ampliada, fue realizada por Alianza Editorial en la colección Libros Singulares, a partir de 2003: volumen I "La sociedad red", volumen II "El poder de la identidad" y volumen III "Fin de milenio".

Chaparro, Enrique A. (2015), “El sistema de voto electrónico de la Ciudad de Buenos Aires: Una ‘solución’ en busca de problemas", en Beatriz Busaniche (comp.), Voto electrónico. Una solución en busca de problemas, edición de Heinrich Böll Stiftung Cono Sur y Fundación Vía Libre, 47 pp. En línea: https://www.vialibre.org.ar/wpcontent/uploads/2015/06/VE.CdBuenosAires.Parte1_.pdf

Comisión Europea (2013), Compendio de Normas Internacionales para las Elecciones, impreso por Albe De Coker, Bélgica, 388 pp. Liga de acceso: http://eeas.europa.eu/eueom/missions/2013/paraguay/pdf/compendium_of_int_standards_3_es.pdf

Commission on Electronic Voting (2004), Secrecy, Accuracy and Testing of the Chosen Electronic Voting System (2004), Reporte Interior, Irlanda, 28 pp. http://www.cev.ie/htm/report/V02.pdf

Comité de Ministros del Consejo de Europa (2004), Recomendación Rec(2004)11 del Comité de Ministros del Consejo de Europa a los Estados miembros sobre los estándares legales, procedimentales y técnicos de los sistemas de votación electrónica, firmada en Estrasburgo el día 30 de septiembre de 2004, http://www.coe.int/t/e/integrated_projects/democracy/02_activities/02_e-voting/01_recommendation/04Evoting\%20Rec\%20Spanish\%20- 
Traducci\%C3\%B3n\%20Rec\%202004\%2011\%20Comit\%C3\%A9\%20Mins\%20Consejo\%20Europa.asp (publicado también por Council of Europe, en 2005, bajo el título Legal, operational and technical standards for evoting: recomendation Rec(2004)11 adopted by the Comittee of Ministers of the Council of Europe on 30 September 2004 and explanaroty memorándum, ISBN 9287156352, 9789287156358, 87 pp.

Comité de Ministros del Consejo de Europa (2005), Legal, operational and technical standards for e-voting, Recomendación Rec(2004)11, Consejo de Europa, 88 pp. Liga de acceso:

http://www.coe.int/t/dgap/democracy/activities/ggis/e-

voting/key_documents/Rec(2004)11_Eng_Evoting_and_Expl_Memo_en.pdf

Conde, Alberto* (2003), Voto electrónico (informe), Buenos Aires, Argentina, 39 pp. *Senador argentino, opositor a la implementación del voto electrónico. Ligas de acceso: http://www.salvador.edu.ar/vrid/iiefgs/trinforme.pdf y http://interfacemindbraincomputer.wetpaint.com/page/2.A.1.1.5.5.-

Valoracion+Etica,+Moral+y+Legal+(Internacional,+Regional+y+local)+de+la+Interaccion?t=anon

Cotino Hueso, Lorenzo (coord.) (2006), "El voto electrónico o la casa por el tejado. La necesidad de construir democracia y participación electrónicas por los cimientos", en Lorenzo Cotino Hueso (coord.), Libertades, democracia y gobierno electrónicos, Comares, Colección Centro de Estudios en Derecho Informático, Granada, España, pp. 171-198 pp. (de 360 pp.). ISBN: 849836003X

Cotino Hueso, Lorenzo (coord.) (2007), Democracia, participación y voto a través de las nuevas tecnologías, Comares, Granada, España, 448 pp. (ISBN: 8498362326. ISBN-13: 9788498362329).

Cotino Hueso, Lorenzo (2007), "Retos jurídicos y carencias normativas de la democracia y la participación electrónicas", en Revista Catalana de Dret Públic núm. 35, ISSN 1885-5709, pp. 75-120. Descarga directa http://documentostics.com/component/option,com_docman/task,doc_download/gid,1395/

Cristiá, Maximiliano (2009), "Introducción al testing de software", Apunte de clase de Ingeniería de Software (Facultad de Ciencias Exactas, Ingeniería y Agrimensura de la Universidad Nacional de Rosario), Argentina, 8 pp. Liga de acceso: http://www.fceia.unr.edu.ar/ingsoft/testing-intro-a.pdf

Culebro Juárez, Montserrat; Wendy Guadalupe Gómez Herrera; y Susana Torres Sánchez (2006), Software libre vs software propietario. Ventajas y desventajas, Creative Commons, México, 170 pp. Liga de acceso: http://www.rebelion.org/docs/32693.pdf

De Cabo, Antonio y José Manuel Sierra (2001), "Sufragio, jueces y democracia en las elecciones norteamericanas de 2000", en Jueces para la Democracia. Información y Debate núm. 40, edición de Jueces para la Democracia, Madrid, marzo de 2001, pp. 76-87. Liga de acceso:

http://www.juecesdemocracia.es/revista/revista\%2040\%20marzo\%202001.pdf

Delgado-Iribarren $\mathrm{G}^{\mathrm{a}}$-Campero, Manuel (2008), "Voto electrónico y nuevas tecnologías", ponencia divulgada por la Fundación Manuel Giménez Abad de Estudios Parlamentarios y del Estado Autonómico, España, en línea, 23 pp. Liga de acceso:

http://portal.uam.es/portal/page/portal/UAM_ORGANIZATIVO/Departamentos/AreasDerecho/AreaDerechoCon stitucional/docenciadelarea/programas1/Materiales/Voto\%20electronico.pdf

Della Gaspera, Jorge; Mario Navarro; y Daniel Rey (2013), Modelo de referencia OSI. Interconexión de Sistemas Abiertos, Informe presentado ante la Facultad Regional Mendoza de la Universidad Tecnológica Nacional, Argentina. En línea: http://www1.frm.utn.edu.ar/comunicaciones/modelo_osi.html

Dendia Aguayo, Rafael* (2004), "Recomendaciones de acciones a tomar para mejorar la aplicación de la tecnología al proceso electoral", en La experiencia reciente de América Latina y su aplicabilidad a un país como Colombia, Memoria del Seminario Internacional sobre Modernización de Procesos Electorales, IIDH, San José de Costa Rica, pp. 103-116. *Magistrado del Tribunal Superior de Justicia Electoral de Paraguay.

Díaz Díaz, Ángel Rafael (2013), "El voto electrónico en México. Las urnas electrónicas y el voto por internet”, 10 pp. Liga de acceso: http://www.diputados.gob.mx/documentos/consejeros_2013/ensayo/24.pdf

Dirección Nacional Electoral (2004), Sistemas electrónicos de votación. Fortalezas y debilidades, publicado por el Ministerio del Interior de la Nación / Dirección Nacional Electoral / Grupo de Trabajo Nuevas Tecnologías y Procesos Electorales, Argentina, 173 pp. Liga de acceso: http://www.joseperezcorti.com.ar/Archivos/Voto_Electronico/2004_MinInt_DiNE_VotoElectronico_Fortalezas_ y_Debilidades_Fernandez_Marcilesse.pdf

Dirección Nacional Electoral (2005), Análisis comparativo: Legislación provincial sobre voto electrónico, publicado por el Ministerio del Interior de la Nación / Dirección Nacional Electoral / Grupo de Trabajo Nuevas Tecnologías y Procesos Electorales, Argentina, 8 de febrero de 2005, 20 pp. Liga de acceso: http://www.mininterior.gov.ar

Dourado de Rezende, Pedro Antonio (2007), “Auditoria, sigilo y desmaterialización del voto ¿Es posible?”, presentado en el $V$ Coloquio Internacional sobre Votación Electrónica, realizado en Monterrey, México, en septiembre de 
2007. En línea: http://www.cic.unb.br/docentes/pedro/trabs/Votobit.html (Reproducido también en el blog smaldone: http://blog.smaldone.com.ar/files/evoto/evoto_brasil_rezende.html).

Feierherd, Guillermo et al (2004), "Una aproximación a los requerimientos de software de voto electrónico en Argentina", comunicación presentada al X Congreso Argentino de Ciencias de la Comunicación, 14 pp. Liga de acceso: http://sedici.unlp.edu.ar/bitstream/handle/10915/22338/Documento_completo.pdf?sequence=1

Feierherd, Guillermo; Armando De Giusti y Beatriz Depetris (2004), "Los sistemas de voto electrónico: requisitos y experiencias", en Anuario 2004, pp. 63-77. Liga de acceso en línea: http://bibliotecavirtual.clacso.org.ar/ar/libros/colombia/dcsupn/practica.pdf http://es.scribd.com/doc/139822275/Voto-Electronico

Feldman, Ariel J.; J. Alex Halderman; y Edward W. Felten (2007), "Security Analysis of the Diebold AccuVote-TS Voting Machine", en Voting Technology Wokshop, agosto de 2007, http://itpolicy.princeton.edu/voting/tspaper.pdf

Fernández Riveira, Rosa María (2001), "El voto electrónico: el caso vasco”, en Revista de Estudios Políticos núm. 112, abril-junio de 2001, pp. 199-236. http://www.cepc.es/rap/Publicaciones/Revistas/3/REPNE_112_201.pdf

Fernández Riveira, Rosa María (2007a), "El voto electrónico: el caso vasco", 36 pp. http://www.monografias.com/trabajos32/voto-electronico-caso-vasco/voto-electronico-caso-vasco.shtml

Fernández Riveira, Rosa María (2007b), "La regulación jurídica del voto electrónico: el ejemplo del caso español”, en aa.vv. Voto electrónico. Estudio comparado en una aproximación jurídico-política (Desafíos y posibilidades), Fundap, Colección Fundap Política y Administración Pública, Querétaro, México, pp. 37-65, (ISBN: 968-543466-9).

Figueroa González, Josué (2006), Arquitectura de seguridad y auditoría para un sistema de voto electrónico, Tesis de Maestría en Ciencias de la Comunicación, Universidad Autónoma Metropolitana - Azcapotzalco, México, 120 pp. Liga de acceso: http://newton.azc.uam.mx/mcc/02_ingles/11_tesis/tesis.html\#area1

Ganuza, Juan José; Karla Perca; y María Fernanda Viecens (2011), "La Redes de Nueva Generación, ¿un nuevo modelo para las telecomunicaciones en España?", en Cuadernos de CICE núm. 81, Ministerio de Economía y Competitividad, España, pp. 243-265. Ligas de acceso:

http://www.revistasice.com/es-ES/CICE/Paginas/TodosLosCuadernos.aspx $\mathrm{http}: / /$ www.revistasice.com/CachePDF/CICE_81__11FC7CEFE35C9D2C3C8A7CD8CF008822.pdf

García Camarero, Ernesto (2012), "La revolución informática", divulgado en Epistemowikia (Revista «Hiperenciclopédica» de Divulgación del Saber”), segunda época, año VII, vol. 6, núm. 4, octubre-diciembre de 2012. Liga de acceso:

http://cala.unex.es/cala/epistemowikia/index.php?title=La_revoluci\%C3\%B3n_inform\%C3\%A1tica Aparecido originalmente en el Cuaderno Historia 16 vía El Granero Común, con liga de acceso: http://archive.is/eGWQt

García Zamora, Claudia Patricia (2005), Diseño y desarrollo de un sistema para elecciones electrónicas seguras (SELES), Tesis de Maestría por el CINVESTAV Unidad Zacatenco - IPN, México, 118 pp. Liga de acceso: http://delta.cs.cinvestav.mx/ francisco/tesis.html

Gentile Martínez, María Rosa (2007), "Monografía del Estado de la Florida”, en Anuario Digital CEMI, en línea, pp. 454546. Liga de acceso: http://www.uh.cu/centros/cemi/wp-content/uploads/2011/11/Mono-Mary-Monografiasobre-el-Estado-de-Florida-2007.pdf

Gritzalis, Dimitris (Ed.) (2003), Secure Electronic Voting, serie Advances in Information Security vol. 7, Hardcover, ISBN: 978-1-4020-7301-4, $240 \mathrm{pp}$.

Guastini, Riccardo (2004), "Proyecto para la voz Ordenamiento Jurídico de un diccionario", en Doxa. Cuadernos de Filosofía del Derecho núm. 27, pp. 247-282. http://descargas.cervantesvirtual.com/servlet/SirveObras/doxa/02415842900573617400080/028049.pdf?incr=1

Heras Lara, Lizbeth y José Luis Villarreal Benítez (2004), "La realidad aumentada: una tecnología en espera de usuarios", en Revista Digital Universitaria núm. 5, volumen 7, Coordinación de Publicación Digitales de la DGSCAUNAM, México, 9 pp. Liga: http://www.revista.unam.mx/vol.8/num6/art48/jun_art48.pdf

Hilbert, Martin y Osvaldo Cairó (2009), ¿Quo vadis, tecnología de la información y de las comunicaciones?, coedición CEPAL / @lis EuropeAid / Mayol Ediciones, Colombia, 372 + XX pp. Liga de acceso: http://allman.rhon.itam.mx/ jincera/quovadistic.pdf

Hoecke, Mark Van (1996), "El uso de principios jurídicos no escritos por los tribunales", en Doxa. Cuadernos de Filosofía del Derecho núm. 19, Universidad de Alicante, España, pp. 421-433. Liga de acceso: http://www.cervantesvirtual.com/servlet/SirveObras/12726106447813728543435/cuaderno19/Doxa19_21.pdf y http://rua.ua.es/dspace/handle/10045/10488

IDEA Internacional (2011), Una introducción al voto electrónico: Consideraciones esenciales, IDEA Internacional, Costa Rica, 41 pp. Liga de acceso: 
http://www.idea.int/publications/introducing-electronic-

voting/loader.cfm?csModule $=$ security/getfile $\&$ pageid $=55458$

IDEA Internacional (2020). Panorama global del impacto del COVID-19 en las elecciones, consultable a través del siguiente link: https://www.idea.int/es/news-media/multimedia-reports/panorama-global-del-impacto-del-covid19-en-las-elecciones.

IFE (2009), CG678/2009. Acuerdo del Consejo General del Instituto Federal Electoral por el que se crea, con carácter temporal, la comisión para realizar las investigaciones y estudios técnicos que permitan determinar la viabilidad o no de utilizar instrumentos electrónicos de votación en los procesos electorales federales. CG678/2009. Fecha de aprobación: 16 de diciembre de 2009. Liga de acceso en línea: http://www.ife.org.mx/docs/IFE-v2/DS/DSGacetasElectorales/2010/gaceta123/pd23.pdf

IFE (2010a), Informe de la Comisión Temporal del Consejo General del Instituto Federal Electoral para realizar las investigaciones y estudios técnicos que permitan determinar la viabilidad o no de utilizar instrumentos electrónicos de votación en los procesos electorales federales, México, $12 \mathrm{pp}$. Liga de acceso: http://www.ife.org.mx/docs/IFE-v2/DS/DS-CG/DS-

ComisionesCG/Temporal_investigacion_estudios_viabilidad_Voto_electronico_CTIEPEF/2010/docs/CVTEInformeFinal.pdf

IFE (2010b), Diagnóstico para Determinar la Viabilidad o No de Utilizar Instrumentos Electrónicos de Votación en los Procesos Electorales Federales, México, 326 pp. Liga de acceso: http://www.ife.org.mx/docs/IFE-v2/DS/DSCG/DS-

ComisionesCG/Temporal_investigacion_estudios_viabilidad_Voto_electronico_CTIEPEF/2010/docs/CVTEDiagnostico.pdf

IFE (2012), CG384/2012. Acuerdo del Consejo General del Instituto Federal Electoral por el que se aprueba la realización de una prueba para el uso de la boleta electrónica el domingo primero de julio de 2012, en los 300 distritos electorales del país. Fecha de aprobación: 7 de junio de 2012. Liga de acceso en línea: http://www.dof.gob.mx/nota_detalle_popup.php?codigo=5256540

IFE (2013), Informe Anual de Actividades enero-diciembre 2012, presentado por le Dirección Ejecutiva de Organización Electoral del Instituto Federal Electoral, con fecha enero de 2013. Liga de acceso en línea: http://www.ife.org.mx/docs/IFE-v2/DS/DS-InformesLegal/DS-InformeAnual/DS-InformeAnual2012/InformeAnual2012-docs/113_DEOE_Inf_Anual_2012.pdf

IFE (2014), Notas en torno a la reglamentación de la reforma constitucional en materia electoral, México. Liga de acceso: http://www.ife.org.mx/docs/IFE-v2/CNCS/CNCS-ComunicadosPrensa/2014/02\%20Febrero/NT.pdf

Irimia, Gerardo (2004), "El sistema electoral y la adopción de nuevas tecnologías en los procesos electorales", en $L a$ experiencia reciente de América Latina y su aplicabilidad a un país como Colombia, Memoria del Seminario Internacional sobre Modernización de Procesos Electorales, IIDH, San José de Costa Rica, pp. 35-49.

Jódar Marín, Juan Ángel (2010), “La era digital: Nuevos medios, nuevos usuarios y nuevos profesionales”, en Razón y Palabra (Primera Revista Digital en Iberoamérica Especializada en Comunicología) núm. 71, año 15, febreroabril de 2010. Ligas de acceso: http://www.razonypalabra.org.mx/anterior.html http://www.razonypalabra.org.mx/N/N71/VARIA/29\%20JODAR_REVISADO.pdf

Juaneda Ayensa, Emma y Leonor González Menorca (2007), "Definiciones, antecedentes y consecuencias del compromiso organizativo", en Juan Carlos Ayala Calvo (coord.), Conocimiento, innovación y emprendedores: camino al futuro, Universidad de la Rioja, España, pp. 3590-3609.

Liga de acceso: http://dialnet.unirioja.es/servlet/libro?codigo=11972

Katz, Claudio (2003-04), "Mito y realidad de la revolución informática", en Eseconomía, IPN, México, invierno 2003-04, pp. 5-21.

Kertzman, Fanny (2013), "Voto electrónico a la venezolana", nota en Semana de 11 de abril de 2013, en línea. Liga de acceso: http://www.semana.com/opinion/articulo/voto-electronico-venezolana/339610-3-

La Red Martínez, David Luis (2002), Sistemas Operativos, Universidad Nacional del Nordeste, Argentina, 926 pp. Liga de acceso: http://exa.unne.edu.ar/depar/areas/informatica/SistemasOperativos/sistope2.PDF

Lizeaga Romero, Itziar (2002), "Voto electrónico en el País Vasco", ponencia presentada en Monterrey, México, sede del Foro sobre Experiencias Internacionales de Voto Electrónico y su Aplicación en México, realizado en octubre de 2002, 29 pp. Liga de acceso: http://www.euskadi.net/botoelek/euskadi/articulos/articulo3.pdf

Luzardo Alliey, Ana Milagro (2009), Diseño de la interfaz gráfica Web en función de los dispositivos móviles, Maestría de Diseño de la Universidad de Palermo, Argentina, 141 pp. Liga:

https://www.palermo.edu/dyc/maestria_diseno/pdf/tesis.completas/43.luzardo.pdf 
Marín Quebrado, Gamaliel y Luis Antonio Gama Moreno (2008), "Emisión de votos a través de dispositivos móviles", en Revista Digital Universitaria núm. 6, volumen 9, DGSCA-UNAM, 10 de junio de 2008, 15 pp.

Martínez Dalmau, Rubén (2006), Voto electrónico, democracia y participación, Vadell Hermanos, Caracas, 88 pp.

Mattelart, Armand (2002), Historia de la sociedad de la información, Paidós, colección Paidós Comunicación, Barcelona, España, 203 pp.

Mercuri, Rebecca T. (1992), "Physical Verifiability of Computers Systems", todos los derechos reservados para la misma autora, 10 pp. Liga de consulta directa: http://www.notablesoftware.com/Papers/PhysVerify.pdf o desde la página web dedicado a Rebecca T. Mercuri, Ph. D.: http://www.notablesoftware.com/rmercuri.html (Datos de catalogación de la Tesis Doctoral, en ProQuest: http://search.proquest.com//docview/251098364)

Mercuri Rebecca (2001), Electronic Vote Tabulation Checks and Balances, Disertación en Computer and Information Science, presentada en las Facultades de la Universidad de Pensiylvania, USA, en cumplimiento parcial de los requerimientos para obtener el grado de Doctor en Filosofía, con UMI número 30003665, directores: Dr. Norman I. Badler y Dr. Val Tannen, todos los derechos reservados para Rebecca T. Mercuri, 235 pp. Liga de acceso directo: http://www.cis.upenn.edu/grad/documents/mercuri-r.pdf

Mercuri, Rebecca (2007), "Rebecca Mercuri's Statement on Electronic Voting", derechos reservados para la autora en 2001 y 2007, en línea. Liga de acceso: http://www.notablesoftware.com/RMstatement.html

Mokate, Karen Marie (2001), Eficacia, eficiencia, equidad y sostenibilidad: ¿Qué queremos decir?, Instituto Interamericano para el Desarrollo Social y Banco Interamericano de Desarrollo, Washington, D. C., 59 pp. Liga: https://inversionsocial.files.wordpress.com/2010/05/bid-criterios-basicos-gerencia-social2.pdf

Nardi, Joel Leandro y Rosa Rita Maenza (2017), "Voto electrónico, vulnerabilidades y soluciones para evitar ataques", comunicación presentada en el XVII Simposio Argentino de Informática y Derecho, 4 al 8 de septiembre de 2017, Facultad Regional Córdoba, pp. 61-71. Liga de acceso: http://sedici.unlp.edu.ar/handle/10915/65209

Obremski, Damián (2006), Sistemas de eVote. Verificabilidad del voto electrónico, Tesis de grado en Ingeniería en Informática, Facultad de Ingeniería de la Universidad de Buenos Aires, diciembre de 2006, 173 pp. Liga de acceso en línea: http://materias.fi.uba.ar/7500/obremski-tesisdegradoingenieriainformatica.pdf

OPE-ACEP (2013), Informe Parcial de Auditoría $N^{\circ}$ 1. Plan de Capacitación Electoral SBUE. Proceso electoral para la elección de cargos provinciales de la Provincia de Salta año 2013, Observatorio Político Electoral de ACEP (OPE-ACEP), Argentina, 40 pp. Liga de acceso: http://www.ope-salta.com/galery/OPE-IA-1.pdf

Otter, Thomas y Mónica Cortez (2003), "Economía de la información, sociedad de la información, información periodística: Elementos compartidos hacia una información pluralista y equitativa", Konrad Adenauer Stiftung, Programa Medios de Comunicación y Democracia en América Latina, en línea, 23 pp. Liga de acceso: http://www.kas.de/wf/doc/kas_4901-1522-4-30.pdf?040622202734

Panach Navarrete, José Ignacio (2010), Incorporación de mecanismos de usabilidad en un entorno de producción de software dirigido por modelos, Borrador de Tesis Doctoral, Universidad Politécnica de Valencia, España, febrero de 2010, 570 pp. Liga de acceso: http://www.dsic.upv.es/docs/bib-dig/tesis/etd-02042010140158/Borrador\%20Ignacio\%20Panach.pdf

Panizo Alonso, Luis (2007), Aspectos tecnológicos del voto electrónico, Oficina Nacional de Procesos Electorales (ONPE) - Gerencia de Capacitación, Investigación y Asistencia Técnica Electoral, Serie Documentos de Trabajo núm. 17, Lima, Perú, ISBN de este número: 978-9972-695-33-9, 54 pp. Acceso desde http://www.onpe.gob.pe/escaparate/escaparate.php. Una versión primaria de este trabajo, publicada en 29 páginas, en 2006, se encuentra en http://www.votobit.org.mx/ponencias/Luis_Panizo.pdf

Panizo Alonso, Luis (2013), Libro blanco del voto electrónico, Observatorio del Voto Electrónico, 50 pp. Liga de acceso: https://buleria.unileon.es/.../Libro\%20blanco\%20sobre\%20el\%20voto\%2...

Pasamar, Abraham (2011), "La prueba pericial informática frente a la impugnación de la autenticidad de un e-mail", documento ppt en imagen pdf, INCIDE, Barcelona, España, 8 de abril de 2011, 15 pp. Liga de acceso: http://www.esade.edu/itemsweb/content/produccion/4010660.pdf

Porras Robles, Rodrigo Antonio (2012), Extensión y mejora de un sistema de votación electrónica para hacerlo más robusto, universalmente verificable, fácilmente usable y práctico, Memoria para optar al título de Ingeniero Civil en Computación, Universidad de Chile, Santiago de Chile, 90 pp. Liga de acceso:

http://users.dcc.uchile.cl/ ahevia/proyectos/evoting/rporras/memoria.pdf

Presno Linera, Miguel Ángel (2001), "Las garantías del derecho de participación política a través del sufragio activo", en Revista de Derecho Político, núm. 52, Departamento de Derecho Constitucional de la UNED, España, pp. 137176. Acceso desde http://web.uniovi.es/constitucional/miemb/presno.htm

Presno Linera, Miguel Ángel (2003), El derecho de voto, Tecnos, Madrid, 271 pp. ISBN 84-309-3934-2 
Presno Linera, Miguel Ángel (2005), "El voto electrónico y el mito de Prometeo”, en Lorenzo Cotino Hueso (coord.), Libertades, democracia y gobiernos electrónicos, Comares, Colección Centro de Estudios en Derecho Informático, Granada, pp. 149-170, http://web.uniovi.es/constitucional/miemb/presno.htm

Presno Linera, Miguel Ángel (2007), "La globalización del voto electrónico", en Lorenzo Cotino Hueso (coord.), Democracia, participación y voto a través de las nuevas tecnologías, Comares, Granada, España, pp. Acceso desde http://www.uniovi.es/constitucional/miemb/presno.htm y http://www.unioviedo.es/constitucional/miemb/presno/La\%20globalizacion\%20del\%20voto\%20electronico.pdf

Presno Linera, Miguel Ángel (2011), El derecho de voto: un derecho político fundamental, Editor: Miguel Ángel Presno Linera, España, 193 pp. Liga de acceso: http://presnolinera.files.wordpress.com/2011/10/el-derecho-de-voto-underecho-polc3adtico-fundamental-libro.pdf

Prince, Alejandro (2005), Consideraciones, aportes y experiencias para el voto electrónico en Argentina, Instituto Tecnología y Desarrollo, Buenos Aires, 94 pp. http://www.spkrsbr.com/biblioteca/htm/Libro_Voto_electronico_\%20Prince.PDF

Prince, Alejandro (2006), Consideraciones, aportes y experiencias para el voto electrónico en Argentina, Editorial Dunken, Buenos Aires, investigación periodística por Enrique Garabetyan, (ISBN 987021732X, 9789870217329).

Prosser, Alexander y Robert Krimmer (2004), "The Dimensions of Electronic Voting Technology, Law, Politics and Society", en Lecture Notes in Informatics 47, número editado por Alexander Prosser y Robert Krimmer, pp. 2128 , http://subs.emis.de/LNI/Proceedings/Proceedings47/Proceeding.GI.47-3.pdfdesde http://subs.emis.de/LNI/Proceedings/

Puiggali, Jordi (2007), "Voto electrónico", ponencia presentada en las II Jornadas de Comercio Electrónico y Administración Electrónica, realizadas el 28 de febrero y 1-2 de marzo de 2007, Universidad de Zaragoza, España, 33 láminas. Liga de acceso: http://jcel.unizar.es/jcel07/ponencias/JCEL_Voto_Electronico.pdf

Reniu Vilamala, Josep $M^{\mathrm{a}}$ (2007), "Los ciudadanos frente al voto electrónico: elementos para una evaluación sociopolítica comparada", en aa.vv. Voto electrónico. Estudio comparado en una aproximación jurídico-política (Desafíos y posibilidades), Fundap, Colección Fundap Política y Administración Pública, Querétaro, México, pp. 67-113, (ISBN: 968-5434-66-9).

Reniu Vilamala, Josep Ma (2008), “Ocho dudas razonables sobre la necesidad del voto electrónico", en Revista de Internet, Derecho y Política núm. 6, pp. 32-44. http://www.uoc.edu/idp/6/dt/esp/democracia_electronica.pdf

Romero Flores, Rodolfo y Julio Alejandro Téllez Valdés (2010), Voto electrónico, derecho y otras implicaciones, IIJUNAM, México, $330 \mathrm{pp}$.

Sáez, Daniel et al (2010), "Tecnologías para la vida independiente y la accesibilidad de los ciudadanos", en Actualidad TIC (Revista del Instituto Tecnológico de Informática) núm. 16, Valencia, España, junio de 2010, pp. 17-23. Liga de acceso: http://www.iti.es/media/about/docs/tic/16/Numero_Completo_16.pdf

Schmelkes, Corina y Nora Elizondo Schmelkes (2010), Manual para la presentación de anteproyectos e informes de investigación (tesis), Oxford, University Press, México, tercera edición, 268 pp.

Sunkel, Guillermo; Daniela Trucco; y Sebastián Möller (2011), Aprender y enseñar con las tecnologías de la información y las comunicaciones en América Latina: potenciales beneficios, coedición de la CEPAL / Unión Europea, serie Políticas Sociales núm. 169, Santiago de Chile, 67 pp. Liga de acceso: http://www.eclac.org/publicaciones/xml/9/42669/sps-169-tics-aprendizajes.pdf

Summers, Robert (2002), "Los principios del Estado de derecho", en Miguel Carbonell, Wistano Orozco y Rodolfo Vázquez (coords.), Estado de derecho. Concepto, fundamentos y democratización en América Latina, coedición Siglo XXI editores / UNAM / ITAM, México, pp. 37-59.

Téllez Valdés, Julio (2008), "Importancia actual del voto electrónico", 20 pp. Liga de acceso: http://portal.uexternado.edu.co/pdf/7_convencionesDerechoInformatico/documentacion/conferencias/Importancia _Actual_del_Derecho_Inform\%C3\%83\%C2\%A1tico.pdf

Téllez Valdés, Julio (2010), El voto electrónico, Tribunal Electoral del Poder Judicial de la Federación, Serie Temas selectos de Derecho Electoral, México, 59 pp.

Téllez Valdés, Julio (2012), "Anotaciones sobre la inconstitucionalidad del voto electrónico en Alemania", en Revista Mexicana de Derecho Electoral núm. 1, México, enero-junio de 2012, pp. 277-274. Liga de acceso: http://biblio.juridicas.unam.mx/revista/pdf/DerechoElectoral/1/esj/esj16.pdf

Téllez Valdés, Julio (2010), "Algunas anotaciones sobre el voto electrónicos”, en César Astudillo y Manlio Fabio Casarín León (coords.), Derecho Constitucional Estatal. Memoria del VIII Congreso Nacional de Derecho Constitucional de los Estados, IIJ-UNAM, México, p. 550-590. 
Tribunal Constitucional Federal de Alemania (2009), “Sentencia 2 BvC 3/07-2 BvC 4/07”, en Justicia Electoral núm. 6, volumen 1, Tribunal Electoral del Poder Judicial de la Federación, México, pp. 509-546. Liga de acceso: http://dialnet.unirioja.es/servlet/articulo?codigo $=4062849 \mathrm{El}$ sitio en donde se puede consultar la versión en alemán de dicha sentencia, es el siguiente: http://www.bverfg.de/entscheidungen/cs20090303_2bvc000307.html

Tuesta Soldevilla, Fernando (2004), "El voto electrónico", en Elecciones núm. 3, pp. 55-80, http://www.onpe.gob.pe/escaparate/download.php?file_name=L-0026.pdf

Urday Chávez, Marco Antonio Alberto (2012), Diseño e implementación de un equipo de voto electrónico, Tesis para optar el título de Ingeniero Electrónico, Facultad de Ciencias de la Pontificia Universidad Católica del Perú, 65 pp. Liga de acceso en línea:

http://tesis.pucp.edu.pe/repositorio/bitstream/handle/123456789/1686/URDAY_MARCO_EQUIPO_VOTO_EL ECTRONICO.pdf?sequence $=1$

Utendorfer, Thilo y Valentin Höbel (2012), "Peinando Logs. Monitorización de logs con Logcheck y Logsurfer”, en Linux Magazine núm. 85, pp. 22-27. Liga de acceso: http://www.linux-magazine.es/issue/85/022-027_MonitorizaciondeFicherosLog_LM85.pdf

Valderrama H., Carlos Eduardo (2012), "Sociedad de la información: hegemonía, reduccionismo tecnológico y resistencias", en Nómadas núm. 36, Universidad Central, Colombia, pp. 13.25. Liga de acceso: http://www.redalyc.org/pdf/1051/105124264002.pdf

Vos, Tanja (2005), "Usabilidad de las aplicaciones informáticas", en Actualidad TIC (Revista del Instituto Tecnológico de Informática) núm. 8, Valencia, España, noviembre de 2005, pp. 1-7. Liga de acceso: http://www.iti.es/media/about/docs/tic/08/articulo2.pdf

Yrivarren, Jorge (2004), "Electrónica y Democracia”, en Elecciones núm. 3, Oficina Nacional de Procesos Electorales (ONPE), Perú, julio de 2004, pp. 109-133. Liga de acceso: http://www.onpe.gob.pe/escaparate/download.php?file_name=L-0026.pdf

Yee, Ka-Ping (2007), Building Realiable Voting Machine Software, Tesis Doctoral en Ciencias de la Computación, University of California, Berkeley, 324 pp. Liga de acceso: http://zesty.ca/pubs/yee-phd.pdf

Zamora Hernández, Jorge y Ana Sanz Esteban (2011), Análisis de los procesos de verificación y validación en las organizaciones software, proyecto fin de carrera, Departamento de Ingeniería del Software, Universidad Carlos III de Madrid, España, 205 pp. Liga de acceso: http://e-archivo.uc3m.es/bitstream/handle/10016/12880/PFC_Jorge_Zamora_Hernandez.pdf?sequence=1

Zetter, Kim (2008), "Votación electrónica: todavía sin soluciones", en PC World núm. 112, octubre de 2008, http://www.pcworld.com.ve/n112/articulos/informe-elecciones2.html 